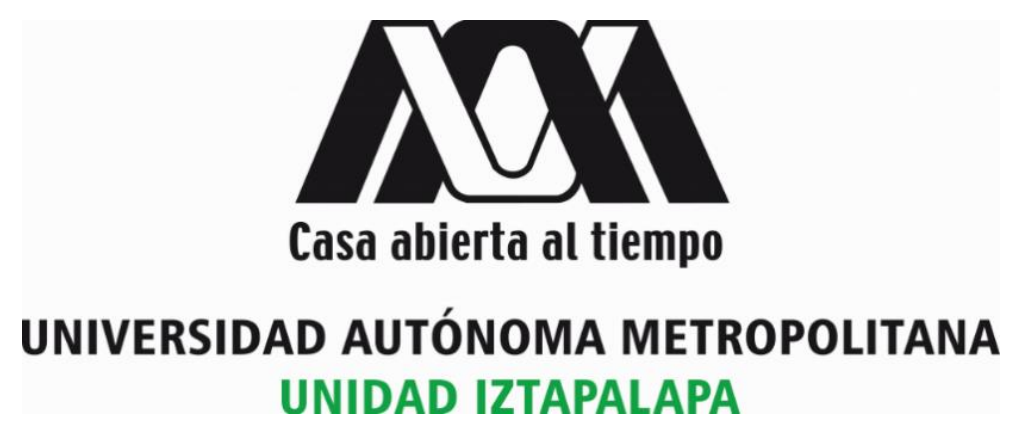

DIVISIÓN DE CIENCIAS BIOLÓGICAS Y DE LA SALUD

MAESTRÍA EN BIOLOGÍA DE LA REPRODUCCIÓN ANIMAL

\title{
“EFECTO DEL ESTRÉS AMBIENTAL Y SOCIAL EN LA REPRODUCCIÓN DE CABRAS CRIOLLAS"
}

\section{TESIS}

\author{
Para obtener el grado de: \\ Maestra en Biología de la Reproducción Animal \\ Presenta: \\ LPA. Mónica Díaz Pacheco \\ Directora: \\ Dra. M. del Socorro I. Retana Márquez. \\ Asesores: \\ Dr. Juan Manuel Vargas Romero, M en C. Susana Rojas Maya
}


COMITÉ TUTORAL

Directora:

Dra. María del Socorro I. Retana Márquez

Depto. Biología de la Reproducción: Biología conductual y reproductiva. UAM-I

rems@xanum.uam.mx

Asesores:

Dr. Juan Manuel Vargas Romero

Depto. Biología de la Reproducción: Sistemas de producción agropecuarios. UAM-I

jmvr@xanum.uam.mx

M. en C. Susana Rojas Maya

Depto. Reproducción: Neuroendocrinología de la conducta reproductiva. UNAMFMVZ

srm@unam.mx 


\title{
JURADO DE EXAMEN
}

Dr. Juan Manuel Vargas Romero

Depto. Biología de la Reproducción: Sistemas de producción agropecuarios. UAM-I

jmvr@xanum.uam.mx

\begin{abstract}
M. en C. Susana Rojas Maya
Depto. Reproducción: Neuroendocrinología de la conducta reproductiva. UNAMFMVZ

srm@unam.mx
\end{abstract}

Dr. José Alberto Delgadillo Sánchez

Departamento de Ciencias Medico Veterinarias

Centro de Investigación en Reproducción Caprina (CIRCA). UAAAN joaldesa@yahoo.com

Dr. Jesús Vielma Sifuentes

Departamento de Ciencias Medico Veterinarias

Centro de Investigación en Reproducción Caprina (CIRCA). UAAAN

jesus_vielm@hotmail.com 


\section{AGRADECIMIENTOS}

Agradezco a:

El Programa de la Maestría en Biología de la Reproducción Animal de la Universidad Autónoma Metropolitana Unidad Iztapalapa, el cual pertenece al Programa Nacional de Posgrados de Calidad con número de registro 003797 del Consejo Nacional de Ciencia y Tecnología, CONACyT.

Al CONACyT por el apoyo otorgado con número de becario 620288 para realizar mis estudios de maestría.

A la Dra. Socorro Retana Márquez por el financiamiento del proyecto a través del convenio SEP-PRODEP 1035-09-1247 
Los miembros del jurado designado por la División de Ciencias Biológicas y de la Salud, Universidad Autónoma Metropolitana Unidad Iztapalapa, abajo firmantes, aprobaron la tesis titulada "Efecto del estrés ambiental y social en la reproducción de cabras criollas". Que presentó: Mónica Díaz Pacheco.

El día 14 de diciembre del 2016.

MIEMBROS DEL JURADO

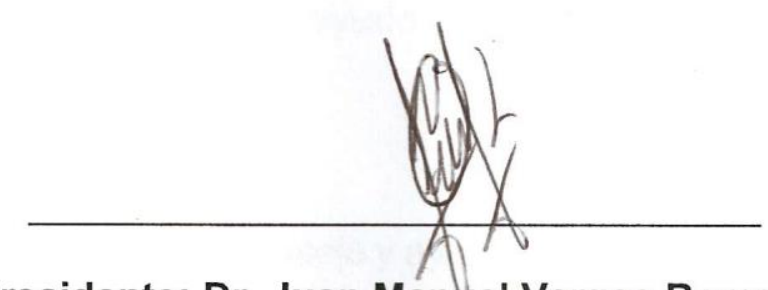

Presidente: Dr. Juan Manuel Vargas Romero

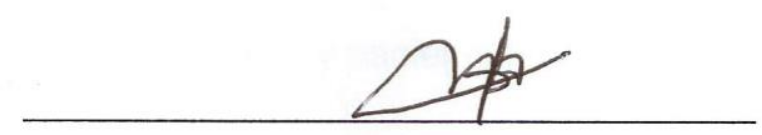

Secretaria: M en C. Susana Rojas Maya

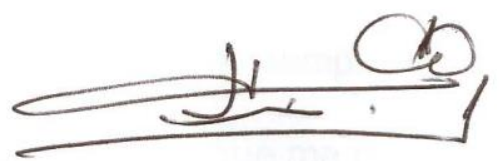

Vocal: Dr. José Alberto Delgadillo Sánchez

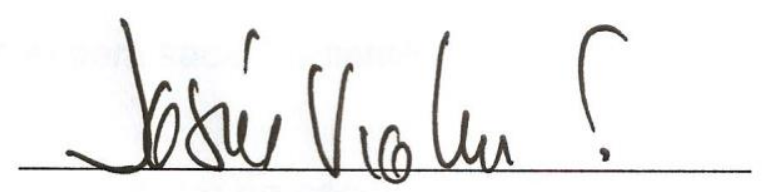

Vocal: Dr. Jesús Vielma Sifuentes 


\section{DEDICATORIAS Y AGRADECIMIENTOS}

Dedico el presente documento de tesis a todas las personas que se interesaron, apoyaron y participaron en su elaboración.

A mi comité tutoral:

La Dra. María del Socorro I. Retana porque además de dirigir el proyecto de investigación y el escrito de tesis, me ayudo a desarrollar nuevas aptitudes durante el posgrado.

Al Dr. Juan Manuel Vargas por su consejo y ayuda durante la investigación y la práctica de campo.

A la Mtra. Susana Rojas por su apoyo y paciencia durante el trabajo de laboratorio.

A mi familia:

A mis padres Agustín y Mireya porque siempre me han alentado a seguir adelante y me han ayudado a cumplir las metas que me propongo. Los quiero mucho!

A mis amigos y colegas de la licenciatura, Rene, Melina, Diego y Azhalea que me ofrecieron todo el apoyo para sacar adelante mi proyecto y

A mi novio Edson que me apoyo en seguir adelante con mis estudios de posgrado, que me brinda ayuda cuando lo necesito, que me escucha y me da consejo para continuar con mis metas. ¡Te amo muchísimo! 
Agradezco:

Al Sr. Florencio y al Sr. Juan Martínez quienes me permitieron trabajar con sus animales y poder desarrollar mi investigación. Además de brindarme todo el apoyo durante mi estancia en la comunidad.

A los alumnos de la Licenciatura en Producción Animal: Rene Rodríguez Florentino, Melina Espinosa Méndez, Diego Vázquez Aguilar, Diana Mendoza Yáñez, Erick Pérez Tavera y Luis Alberto Chávez quienes me apoyaron en el manejo de los animales.

A mis compañeros del laboratorio, Azhalea, Liz, Sergio, Flor, Eunice, Diana, Felipe, Ángeles y Fahiel, que estuvieron apoyándome en cada sesión de seminario para enriquecer mi trabajo. ¡Gracias chicos, los quiero mucho! 


\section{INDICE}

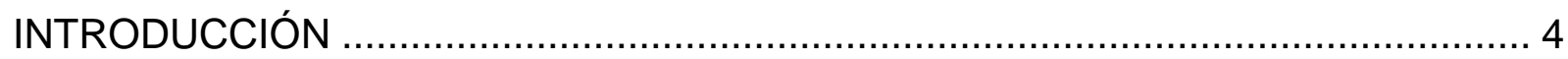

Situación actual de la caprinocultura en México....................................................... 4

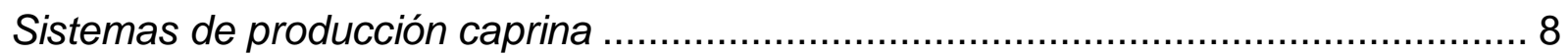

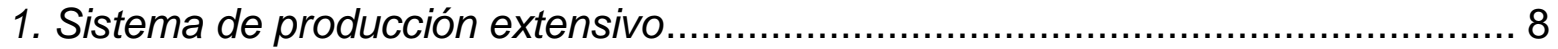

2. Sistemas de producción semi-intensivo .............................................................. 9

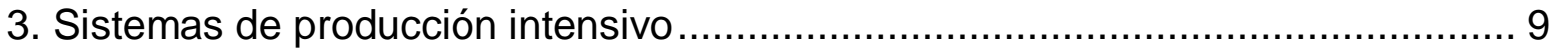

Reproducción de los caprinos y la estacionalidad ................................................ 11

Endocrinología de la reproducción en los caprinos ............................................... 13

Reproducción en la hembra ............................................................................. 15

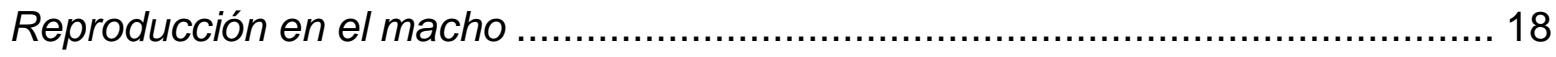

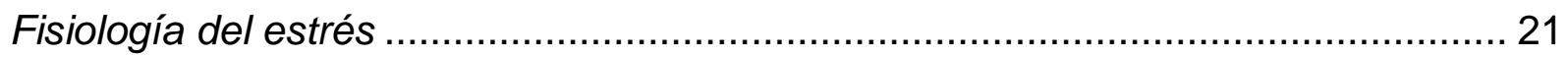

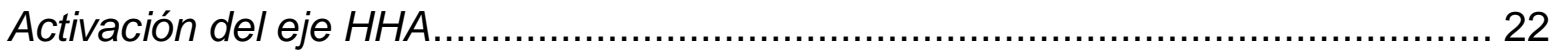

Factores que pueden afectar la reproducción ........................................................... 22

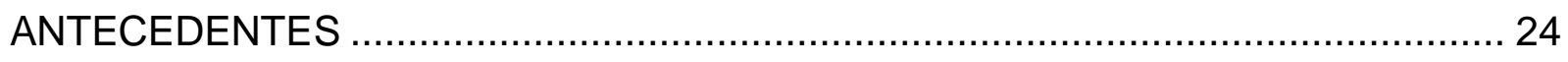

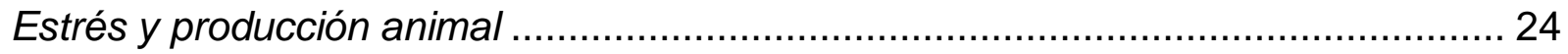

Interacción social y Hacinamiento ....................................................................... 24

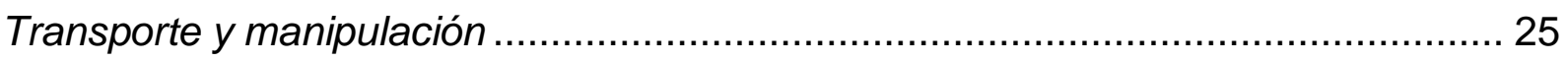

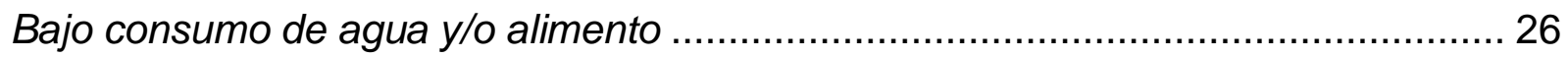

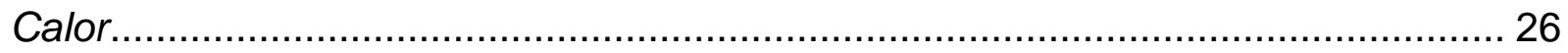

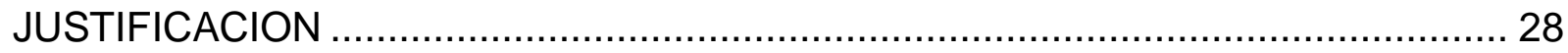

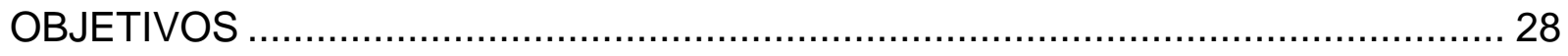

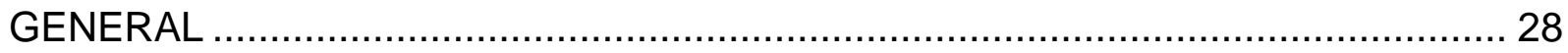

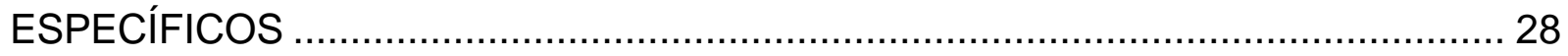

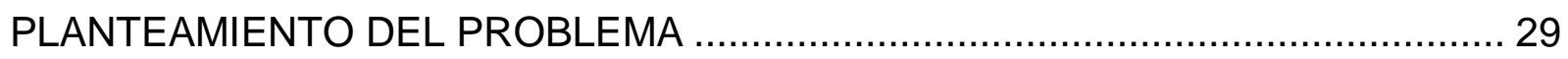




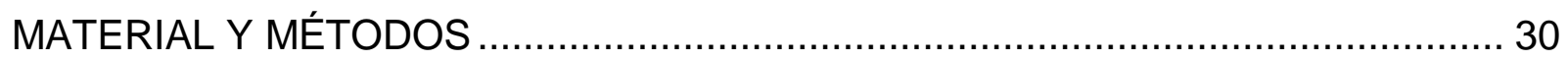

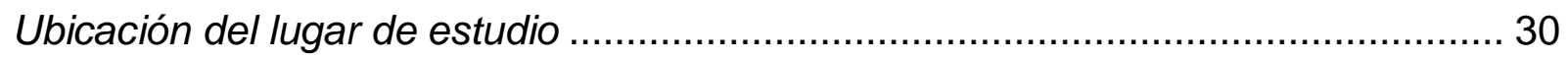

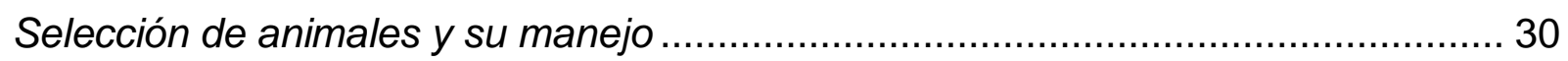

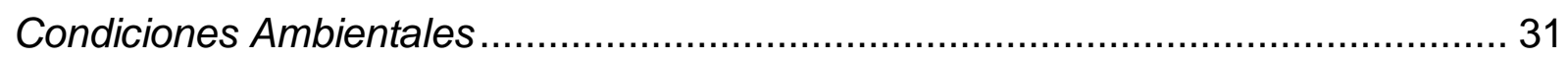

Obtención y procesamiento de las muestras sanguíneas ....................................... 31

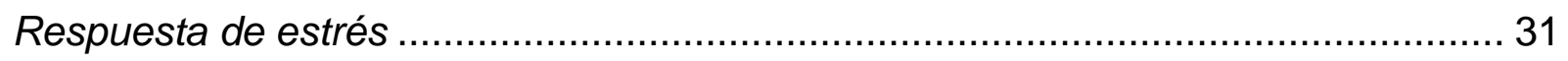

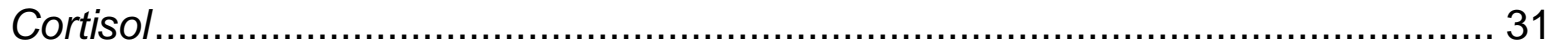

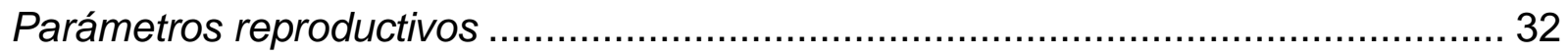

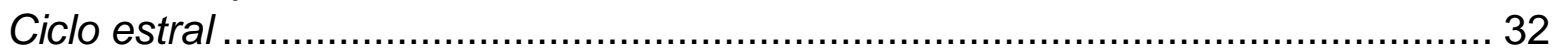

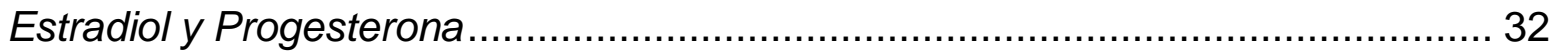

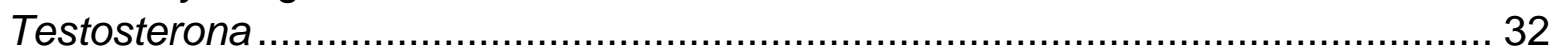

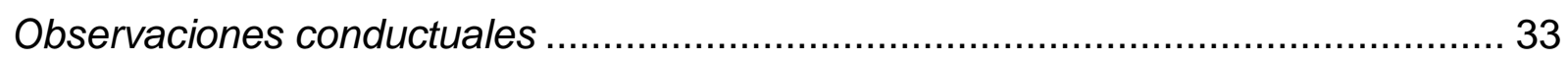

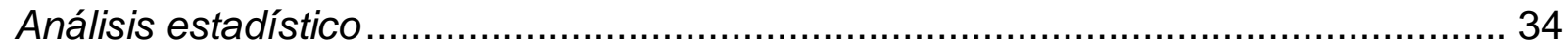

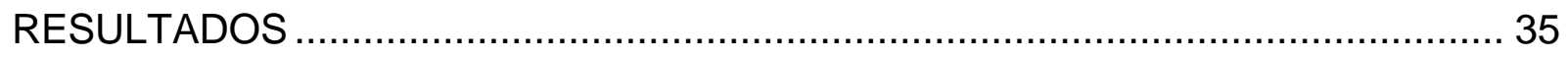

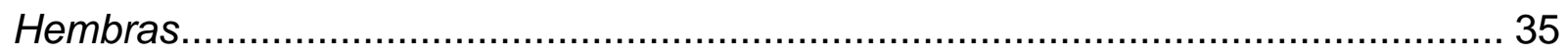

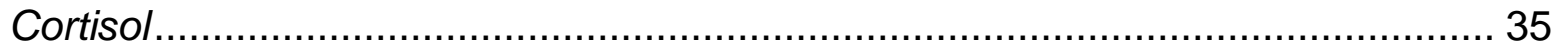

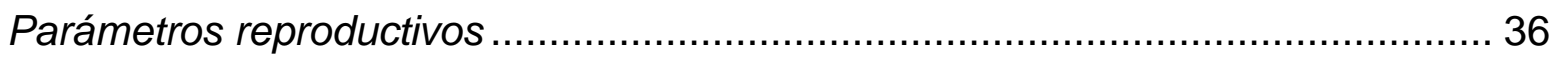

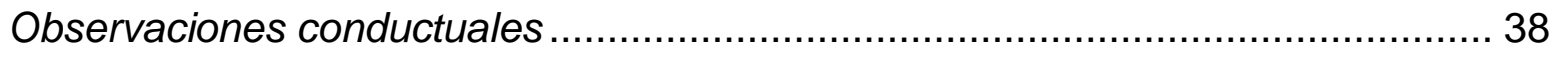

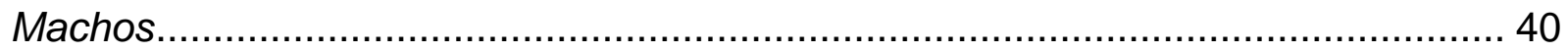

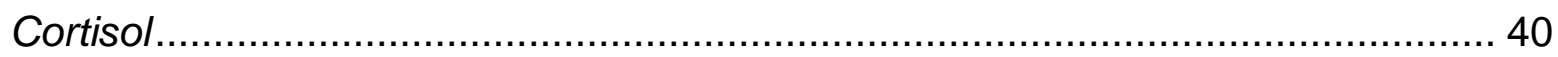

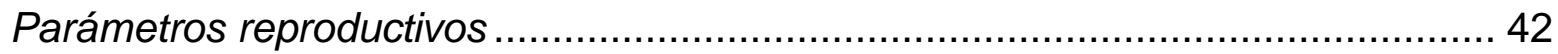

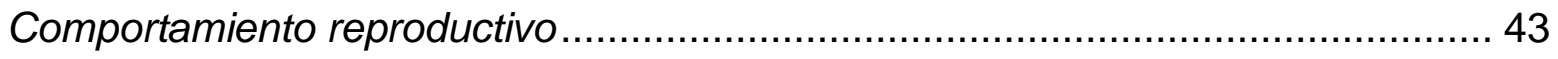

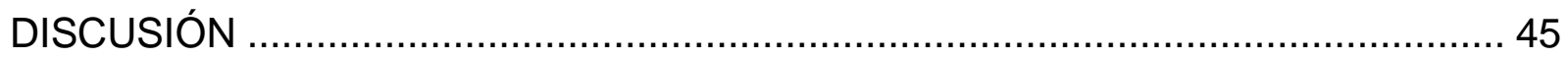

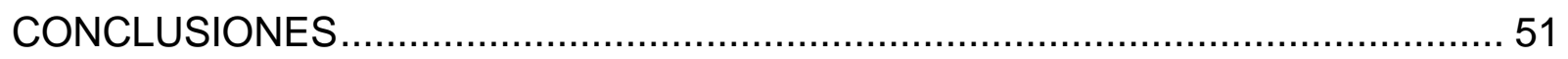

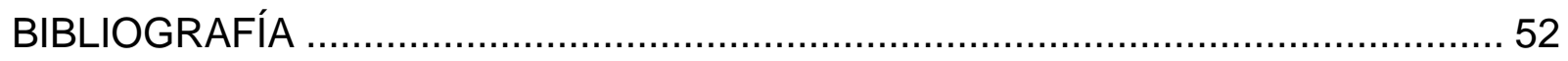





\section{Resumen}

La reproducción es el principal factor que determina la rentabilidad en un sistema de producción y el estrés puede afectar la eficiencia reproductiva. Sin embargo, actualmente se desconoce el grado en que el estrés afecta la reproducción de las cabras. Por lo tanto, el objetivo de este trabajo fue evaluar el efecto del estrés por hacinamiento y restricción de agua en la expresión del comportamiento reproductivo y nivel de hormonas sexuales de cabras criollas de la región Mixteca Oaxaqueña. Se asignaron 10 hembras, 7 machos y un semental al grupo control (espacio $2 \mathrm{~m}^{2} / \mathrm{cabra}$ dentro del corral y suministro de agua diaria); al grupo de estrés se asignaron 10 hembras, 9 machos y un semental (condiciones a las que están habituadas: espacio $40 \mathrm{~cm}^{2} /$ cabra y sin suministro de agua dentro del corral, solo la ingerían durante el pastoreo). Ambos grupos se alimentaron en pastoreo en un tiempo de 6 horas por día. Se mantuvieron así por seis meses (Septiembre 2015 a Febrero 2016). Posteriormente se evaluó la expresión de la conducta reproductiva en machos y hembras mediante un etograma. Al iniciar la actividad reproductiva, el 15 de Enero 2016 se tomaron muestras de sangre de la vena yugular, cada 3 horas, por un periodo de 24 horas para evaluar la variación circadiana del cortisol en respuesta al estrés de machos y hembras. En las hembras, se evaluaron las concentraciones de estradiol y de progesterona durante la etapa de estro (Fase folicular) y diez días después del estro (Fase lútea). En los machos se evaluaron los niveles de testosterona antes y durante la actividad reproductiva (Diciembre 2015 y Enero 2016 respectivamente). Los resultados muestran que los niveles de cortisol en los animales estresados mantienen su variación de cortisol, pero en niveles significativamente mayores que en los controles. El estradiol y la progesterona en las hembras estresadas fueron menores que en las hembras control. Los niveles de testosterona en los machos del grupo control fueron mayores que en los machos estresados en los tiempos evaluados (antes y durante la reproducción). Tanto los machos como las hembras estresadas presentaron menor número de conductas reproductivas en comparación con los animales no estresados. Estos resultados indican que, a pesar de que las cabras están habituadas a las 
condiciones en las que se mantienen en la Región Mixteca de Oaxaca, sus parámetros fisiológicos reproductivos muestran que dichas condiciones son factores estresantes para ellas, pues la actividad del eje adrenal es superior a las cabras control. Dicha activación del eje adrenal en respuesta al estrés ambiental podría estar repercutiendo en la disminución de los niveles séricos de estradiol en las hembras y de testosterona en los machos, así como en la expresión de su comportamiento reproductivo. 
Abstract

Reproduction is the main factor that determines profitability in an animal production system and stressful conditions can disrupt the reproductive efficiency. However, currently it is unknown how stress disturbs reproduction in goats. Therefore, the aim of this study was to evaluate the effects of stress by overcrowding and water restriction (living conditions) in the reproduction of native goats of the Oaxaca Mixteca Region. Control group consisted of 10 females, 7 males and stallion male (space $2 \mathrm{~m}^{2} /$ goat, with daily water supply); stress group consisted of 10 females, 9 males and stallion male (in conditions to which they are accustomed: space $0.4 \mathrm{~m}^{2} /$ goat, with water restriction). The study was conducted during for six months (September 2015-February 2016); the expression of reproductive behavior was evaluated using an ethogram. At the beginning of the reproductive activity, on January 15, 2016, Blood samples were taken every 3 hours from the jugular for a period of 24 hours in both groups in order to assess the variation of cortisol in males and females. In females the concentration of estradiol and progesterone was evaluated during the estrous cycle. In males, testosterone levels were evaluated before and during reproductive activity. The results show that although cortisol levels maintain their variation of cortisol, they are significantly higher in stressed animals compared with controls. Also, significant differences in sex hormones in females were found. Estradiol levels in females were significantly lower compared with control females. Testosterone levels in stressed males were lower than in control males both before and during reproduction. These results indicate that even goats from Oaxaca Mixteca Region are habituated to their environmental conditions, they remain being stressors for them, as the activation of adrenal axis is higher than in control goats. High cortisol levels may induce low estradiol levels in females and low testosterone levels in males, as well as disrupted expression of their reproductive behavior. 


\section{INTRODUCCIÓN}

\section{Situación actual de la caprinocultura en México}

En México, alrededor de 1.5 millones de personas tienen como actividad productiva primaria o complementaria la caprinocultura en 494 mil unidades de producción (Aréchiga et al., 2008), principalmente en zonas áridas y semiáridas, donde existe un bajo índice de desarrollo humano, es decir, la posibilidad de gozar de una vida larga y saludable, educación y el acceso a recursos e ingresos para gozar de una vida digna. En el 2010, la marginación socioeconómica en el país fue de 16.8 \% de la población total, y los estados con mayor nivel de marginación fueron: Chiapas, Guerrero, Oaxaca, Veracruz, Hidalgo, Puebla, Tabasco, Michoacán, San Luis Potosí, Yucatán, Campeche y Zacatecas, incrementando en más de 19\% la marginación socioeconómica en cada estado (CONAPO, 2010).

De acuerdo con las cifras proporcionadas por el Sistema de Información Agroalimentaria y Pesquera (SIAP) en el año 2014, la población de ganado caprino fue de 8,687,814 cabezas, con una producción de 77,824 toneladas de carne, considerándose la cifra más baja de la última década (Figura 1). Las principales limitantes por las que se ha dado ésta disminución son la insuficiente infraestructura en la producción, y el rezago tecnológico y sanitario. En la producción de carne caprina por estados destacan cinco estados, algunos del norte y otros de la Mixteca: Coahuila, Zacatecas, Puebla, Oaxaca y Guerrero, aportan el 52\% de la producción del país (SIAP, 2014). San Luis Potosí, Michoacán, Tamaulipas, Guanajuato y Nuevo León contribuyen con el 26\%; el 22\% que complementan el total, lo aportan el resto de los estados (Figura 2). 


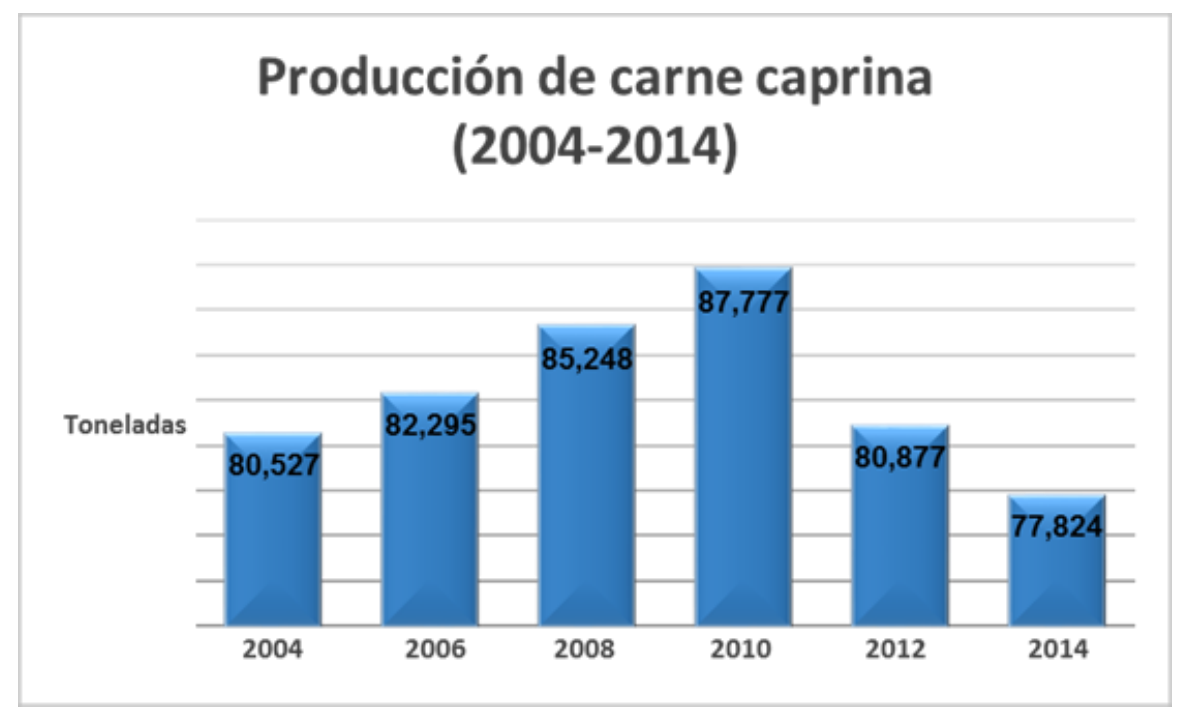

Figura 1. Registro de la producción nacional de carne de ganado caprino del año 2004 al 2014 en México. Datos obtenidos del Servicio de Información Agroalimentaria y Pesquera (SIAP), 2014

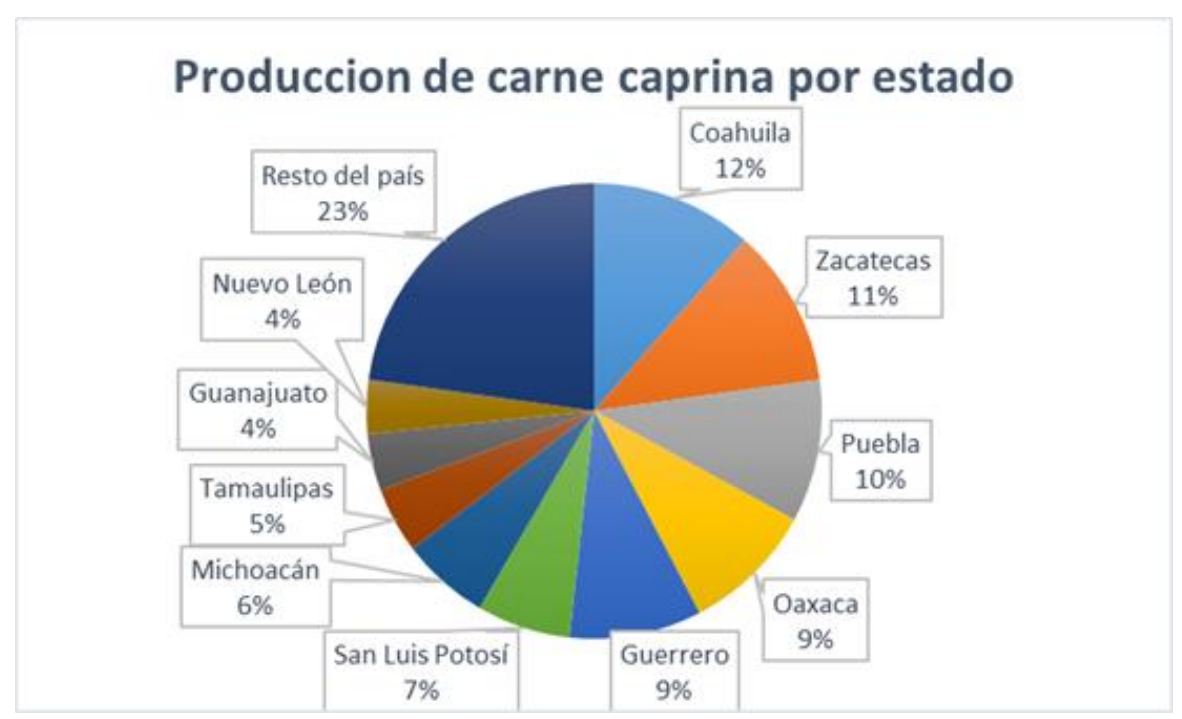

Figura 2. Registro de la producción de carne caprina por estado. Datos obtenidos del Servicio de Información Agroalimentaria y Pesquera (SIAP), 2014 
Con respecto a la producción de leche, la tendencia también ha ido a la baja, ya que el descenso entre 2010 (161,796 miles de litros) y el 2014 (155,497 miles de litros) es del 3.8\% (Figura 3). Tres estados contribuyeron en el 2014 con el $72 \%$ del total de la producción en el país: Coahuila 31\%, Guanajuato 25\%, Durango, 16\%. Estos estados están localizados en las zonas especializadas en la producción de leche, como son la Laguna y el Bajío (Figura 4).

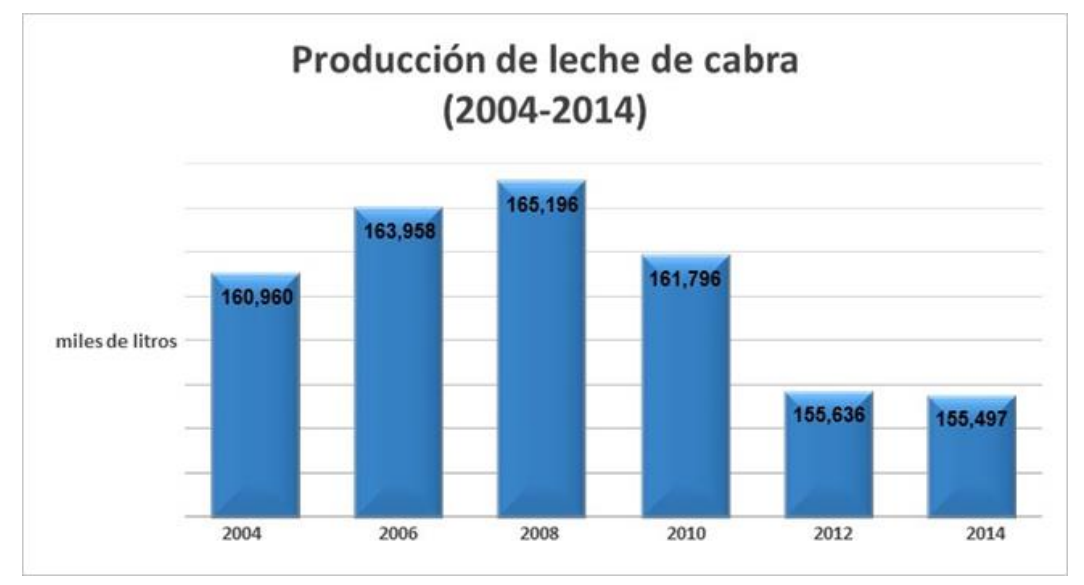

Figura 3. Registro de la producción nacional de leche caprina del año 2004 al 2014 en México. Datos obtenidos del Servicio de Información Agroalimentaria y Pesquera (SIAP), 2014

\section{PRODUCCION DE LECHE DE CABRA 2014}

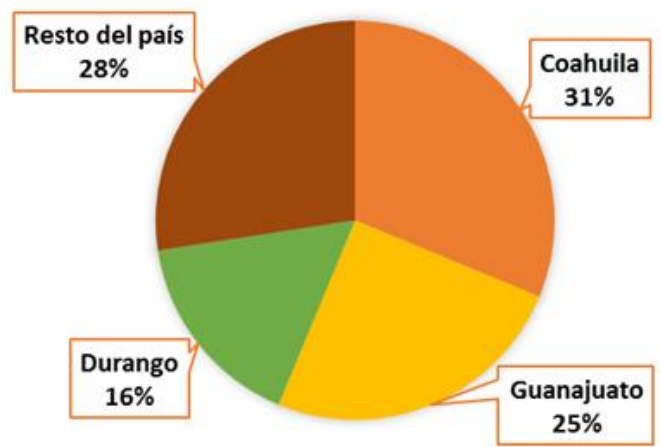

Figura 4. Registro de la producción de leche caprina por estado. Datos obtenidos del Servicio de Información Agroalimentaria y pesquera (SIAP), 2014 
La región Mixteca comprende a los tres estados con mayor índice de marginación socioeconómica: Guerrero, Oaxaca y Puebla (CONAPO, 2010). En dicha región se encuentra el $37 \%$ de la población caprina, aproximadamente 3,137,355 caprinos (CNOG, 2012) (Figura 5). La Mixteca abarca una superficie aproximada de 40, 000 $\mathrm{km}^{2}$, con 18,759 $\mathrm{km}^{2}$ ubicados en el estado de Oaxaca. De acuerdo con las características geográficas, la Mixteca se divide en Mixteca Alta, Mixteca Baja y Mixteca de la costa (Hernández et al., 2011). La Mixteca baja Oaxaqueña es una de las regiones más pobres de México, con mayor deterioro del suelo, altos niveles de deforestación (Altieri et al., 2006) y escasez de agua en gran parte de las comunidades que la comprenden (Guerrero et al., 2010).

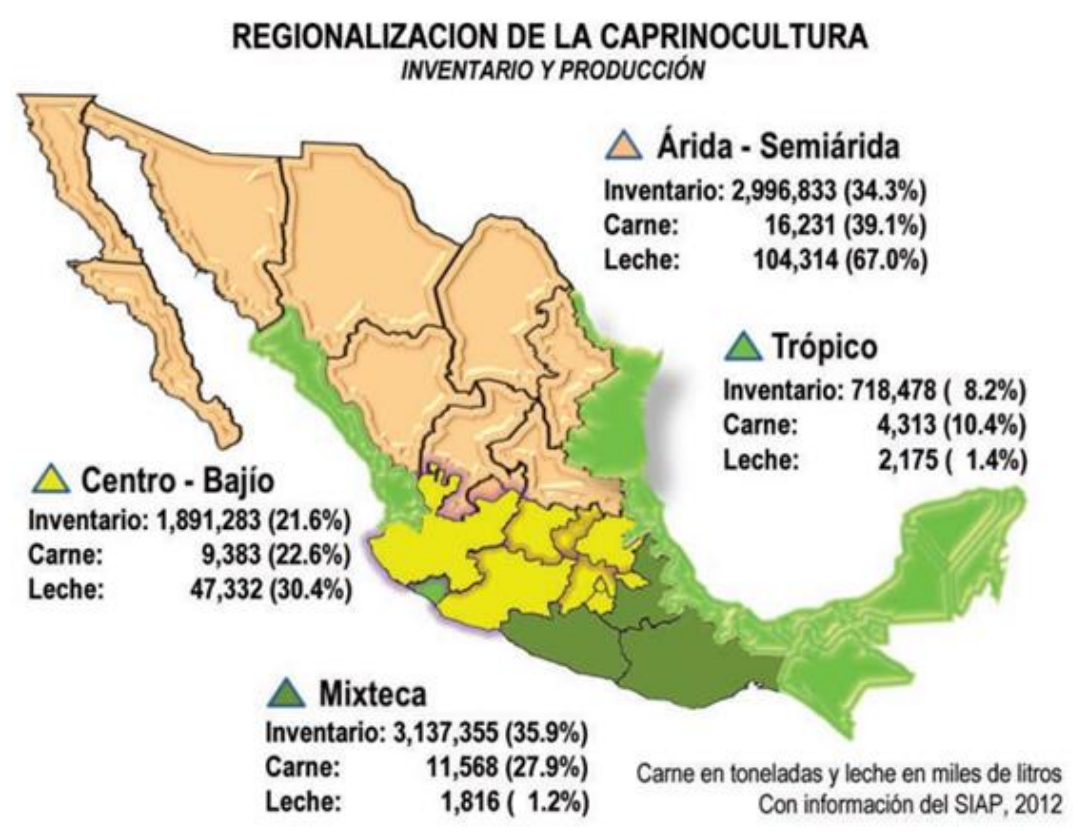

Figura 5. Regionalización de la caprinocultura en México. La región Mixteca concentra el mayor porcentaje con un $35.9 \%$ de cabezas de ganado caprino. Seguido la zona ÁridaSemiárida con $34.3 \%$ y el Centro-Bajío con el 21.6\%. Tomado de Comité Nacional Sistema producto caprinos 2012 


\section{Sistemas de producción caprina}

Los sistema de producción caprina dependen de varios factores tales como el clima, la extensión del terreno disponible, la cantidad de cabras en el rebaño, medidas para confinarlas dentro de cierta área y el objetivo de la explotación, que puede ser: leche, carne, doble propósito, piel o venta en pie. En México, las unidades de producción caprina se dividen en 3 sistemas de producción:

\section{Sistema de producción extensivo}

Este sistema se utiliza en climas desérticos, las cabras criollas originarias o adaptadas a las difíciles condiciones del medio, ingieren su alimento recorriendo extensas áreas para alimentarse de arbustos y pastos disponibles en la región. Durante la época de sequía hay gran escasez de agua, el forraje es seco y de baja calidad, con deficiencia de proteína bruta, bajo contenido de azúcares solubles, almidón y fibra con alto grado de lignificación. Haciendo que el aporte de nutrientes para el animal sea escaso. Exhiben pobres y deficientes programas de manejo (instalaciones, nutrición, reproducción, mejoramiento genético, salud y mercado). Este sistema posee varias modalidades y puede ser sistema de producción trashumante, sistema de producción sedentario o sistema de producción nómada modificado (Manuales del ganado caprino, s.f., Hernández, 2000).

a) Sistema de producción trashumante

Se caracteriza por el pastoreo en diferentes áreas, en continuo movimiento, recorriendo largas distancias hasta llegar a zonas con más alimento disponible (Berumen, 2004), se mueven según el pastizal y dependiendo de la estación del año, así como de las condiciones climáticas. Tiene como objetivo principal la carne y venta de cabrito. 
b) Sistema de producción sedentario

Este sistema se caracteriza porque el productor tiene su hato en un lugar fijo. El ganado sale a pastorear a diferentes lugares durante el día, se alimenta de pastizales y matorrales y regresa al corral por la noche. Utiliza la vegetación según la época y condición del pastizal, sin medidas de mejorar ni aumentar la producción, ni medidas de conservación de suelo ni vegetación. Las crías no andan con la madre y se les deja en el corral. Este sistema tiene el problema de que los animales deben recorrer de 8 a $12 \mathrm{Km}$ diarios. Tiene como objetivo la producción de carne.

c) Sistema de producción nómada modificado.

Se considera el sistema más primitivo, el pastor va buscando comida y agua, no existen lugares de crianza fijos y carece de técnicas para manejar y conservar el pastizal, dando como resultado baja productividad.

\section{Sistemas de producción semi-intensivo}

Se caracteriza por la combinación del pastoreo en praderas, ramoneo en matorrales y utilización de fuentes alimenticias de regular calidad nutritiva, así como de la posibilidad de suplementar con granos y forrajes. Aún se tienen construcciones rústicas pero que brindan un mayor bienestar a los animales (Fuente et al., 1989). Los productos principales son la leche, cabras para cría y sementales para venta.

\section{Sistemas de producción intensivo}

Se practica en las unidades lecheras de alta producción, con alto rendimiento biológico y donde los animales están confinados permanentemente, suministrándoseles el alimento en el corral (forrajes de corte, granos y esquilmos). Los productos principales son la leche y la venta de reproductores (Hernández, 2000). 
En México, el 90\% de los sistemas de producción caprina son pastoriles de tipo sedentario (Hernández et al., 2011). Las actividades pecuarias en las comunidades rurales de la región Mixteca, tiene como principal frecuencia a la unidad de producción caprina de tipo familiar, donde además de las características ya mencionadas sobre el sistema pastoril sedentario, los riesgos en la producción pecuaria, los asume el productor y los minimiza con la producción alterna de la agricultura u otras actividades (Hernández et al., 2001). El número promedio de cabras de los rebaños que se encuentran en la región Mixteca normalmente no supera las 50 cabras criollas y, el objetivo principal es la producción de carne para venta y autoconsumo.

En la Mixteca baja Oaxaqueña el terreno es montañoso, su nombre se debe a que su altura varía entre los 1,200 y los 1,800 metros sobre el nivel del mar (msnm). En la Mixteca Alta, la altitud supera los 2,000 msnm y en la Mixteca de la Costa, las altitudes disminuyen hasta conformarse como parte de la región de la Costa. A consecuencia de la variación de las alturas, en general, las características climáticas son muy extremosas y cambiantes; el clima es de tipo desértico y semidesértico, seco y frío en gran parte de la Mixteca Oaxaqueña (Berumen, 2004), excepto por las precipitaciones en verano, que varían entre los 300 y $800 \mathrm{~mm}$ anuales distribuidos entre Julio y Septiembre (García, 2004, Arias et al., 2012). La temperatura mínima en invierno es de $4^{\circ} \mathrm{C}$ y en verano se superan los $37^{\circ} \mathrm{C}$, mientras que la media anual es $19^{\circ} \mathrm{C}$ (Soriano et al., 2011), esto es característico en gran parte de la Mixteca. La vegetación predominante son árboles de huizache (Acacia farneciana), cazaguate (Ipomoea arborescens), guamúchil (Pithecellobium dulce), cubata (Acacia cochliacantha), huaje (Leucaena esculenta) y mezquite (Prosopis glandulosa). Así como algunas variedades de cactáceas dulces como la pitaya (Stenocereus proinosu), el jiotillo (Escontría chiotilla) y el xoconostle dulce (Stenocereus stellatus) (INAFED, 2010), todos éstos susceptibles de ser consumidos por el ganado. 
Reproducción de los caprinos y la estacionalidad

La reproducción es una función indispensable para la perpetuación de la especie. La estacionalidad ha sido una estrategia reproductiva para seleccionar la época del año más favorable para el nacimiento de las crías y asegurar su supervivencia (Bronson y Heideman, 1994). En cabras y ovejas la estacionalidad reproductiva depende de diferentes factores como la latitud, el clima, la raza, el estado fisiológico, la presencia del macho, el sistema de cría y principalmente el fotoperiodo (González, 1993, Escobar, 2000). En las zonas templadas, el ciclo anual del fotoperíodo es la principal fuente de información ambiental responsable de los cambios estacionales en la actividad reproductiva. En las zonas tropicales y subtropicales, donde la amplitud de la variación anual de la duración del día disminuye en función de la latitud, la función del fotoperiodo se reduce y otros factores ambientales pueden influir en la estacionalidad (Duarte et al., 2008). Es por esto que algunas razas caprinas originarias o adaptadas a las regiones subtropicales presentan estacionalidad (Delgadillo et al., 1999) con una etapa de anestro más corta (Valencia et al., 1986). Las hembras de zonas templadas presentan varios ciclos estrales, conducta de estro y ovulación únicamente en una estación determinada del año, en la Figura 6 se puede observar que la estación reproductiva inicia a principios de otoño, cuando la duración de los días es más corta (Chemineau et al., 1992). En el macho, durante esta temporada la espermatogénesis se mantiene activa. Durante los días largos, se presenta un anestro estacional, con ausencia de ciclos estrales regulares, receptividad sexual y ovulación. En el macho, cesa la espermatogénesis y la libido. 


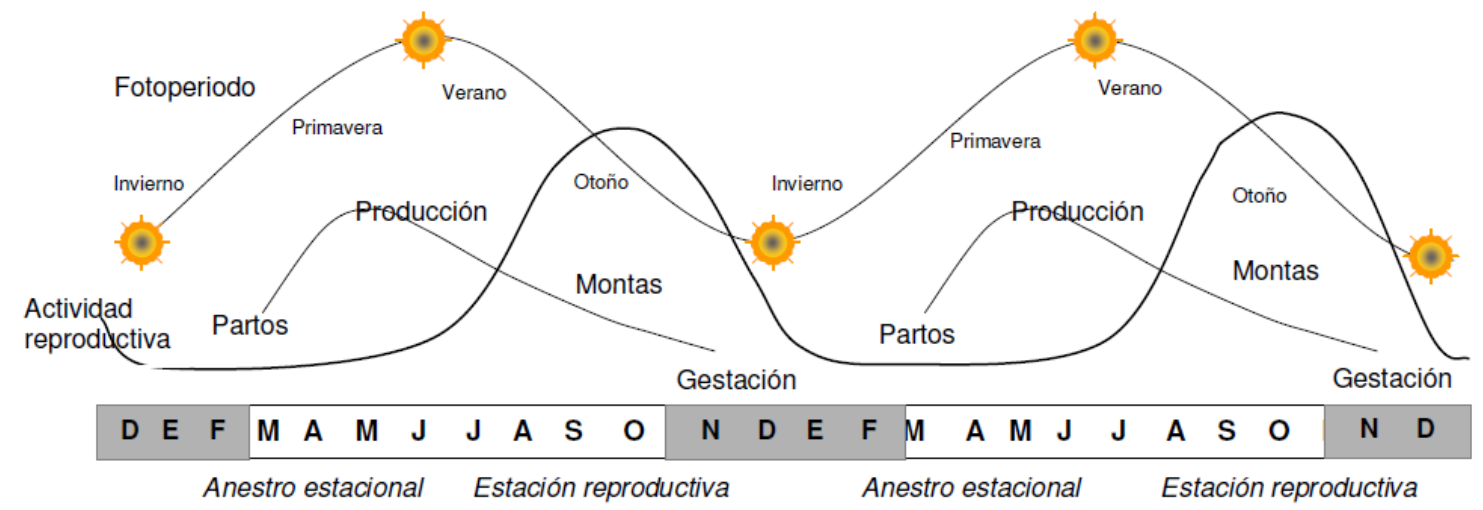

Figura 6. Representación de la estacionalidad reproductiva de los caprinos. Los cambios en la duración del fotoperiodo a lo largo del año son mayores en latitudes lejanas al ecuador. A esas latitudes la actividad reproductiva inicia cuando la cantidad de horas luz disminuye. Tomado de Álvarez y Ducoing, 2009.

En las zonas tropicales no se observan modificaciones lumínicas tan marcadas como las de zonas templadas, sin embargo, se ha observado cierta estacionalidad reproductiva en ovejas y cabras bajo estas condiciones (Ferraro et al., 2009). En la región Mixteca, la estacionalidad reproductiva de la población caprina requiere de estudio, aunque se ha reportado que el mayor número de cabras gestantes ocurre entre julio y octubre (Hernández et al., 2001).

\section{Control neuroendocrino de la estacionalidad reproductiva}

Los animales estacionales como cabras y ovejas, detectan las variaciones anuales en la duración del fotoperiodo, utilizan una compleja red neural a nivel central y transforman la señal luminosa en una señal hormonal a través de la síntesis y secreción de melatonina (Mapaux et al., 1999, Barrell et al., 2000). En este mecanismo, la luz es captada en el ojo a través de la retina, la señal luminosa se transforma en una señal eléctrica que es conducida de la retina al hipotálamo por medio del tracto retinohipotalámico. En el hipotálamo, el núcleo supraquiasmático capta la señal y la transfiere al núcleo paraventricular, finalmente la señal llega al ganglio cervical superior 
(Arendt, 1998). Es aquí, cuando la señal eléctrica se transforma en una señal química; el ganglio cervical superior libera noradrenalina, la cual es captada por receptores en la membrana celular de los pinealocitos e induce la síntesis de la $\mathrm{N}$-acetil-transferasa, enzima que es requerida para la síntesis de melatonina (Arendt, 1998). La menor duración en la secreción de melatonina durante los días largos, permite la síntesis de dopamina e induce el anestro estacional. Durante los días cortos, la mayor duración en la síntesis y secreción de melatonina inhibe la producción de dopamina, con el subsecuente restablecimiento de la actividad estral (Arroyo, 2011). Durante el anestro, el estradiol, cuya concentración es basal, ejerce un efecto de retroalimentación negativa a nivel hipotalámico, actúa específicamente en el núcleo dopaminérgico Al5, donde induce la síntesis y secreción de dopamina, inhibiendo la síntesis y liberación de $\mathrm{GnRH}$ (Arroyo, 2011).

\section{Endocrinología de la reproducción en los caprinos}

La reproducción en cabras está regulada por la función del eje hipotálamo-hipófisisgónada $(\mathrm{HHG})$, que inicia con la secreción pulsátil de la hormona liberadora de gonadotropinas $(\mathrm{GnRH})$ de las neuronas que se encuentran en el Área Preóptica media (MPOA) y están bajo el control de la Kisspeptina (Pinilla et al., 2012) liberada del núcleo arcuato y del núcleo Anteroventral Periventricular (AVPV), así como de la Hormona Inhibidora de Gonadotropinas $(\mathrm{GnIH})$ desde el Núcleo Ventromedial (VMH) del hipotálamo (Herbison, 2006; Smith y Clarke, 2010) y otros neuropéptidos metabólicos, tales como el neuropéptido $Y$ (NPY) y la neuroquinina $B$ (NKB) en el núcleo arcuato (Lehman et al., 2010).. Por tanto, la generación de pulsos de $\mathrm{GnRH}$ es determinada por la acción dinámica de señales excitadoras e inhibitorias que provienen de todos estos factores. La GnRH es transportada a la eminencia media del hipotálamo y liberada en el sistema porta-hipofisiario, por donde viaja hasta llegar a la adenohipófisis, donde actúa sobre los gonadotropos para estimular la síntesis y liberación de la hormona luteinizante ( $\mathrm{LH}$ ) y la hormona folículo estimulante (FSH), las cuales a su vez actúan sobre las gónadas para estimular la síntesis y liberación de 
hormonas esteroides gonadales (Tanriverdi et al., 2003). La activación del eje HHG es regulado por mecanismos de retroalimentación negativa y positiva sobre el hipotálamo y la adenohipófisis (Figura 7). La testosterona conduce acciones inhibitorias sobre la secreción de GnRH en el macho, mientras que los esteroides ováricos, principalmente estradiol y Progesterona, puede llevar a cabo ambas acciones de retroalimentación negativa y positiva dependiendo de la etapa del ciclo ovárico.

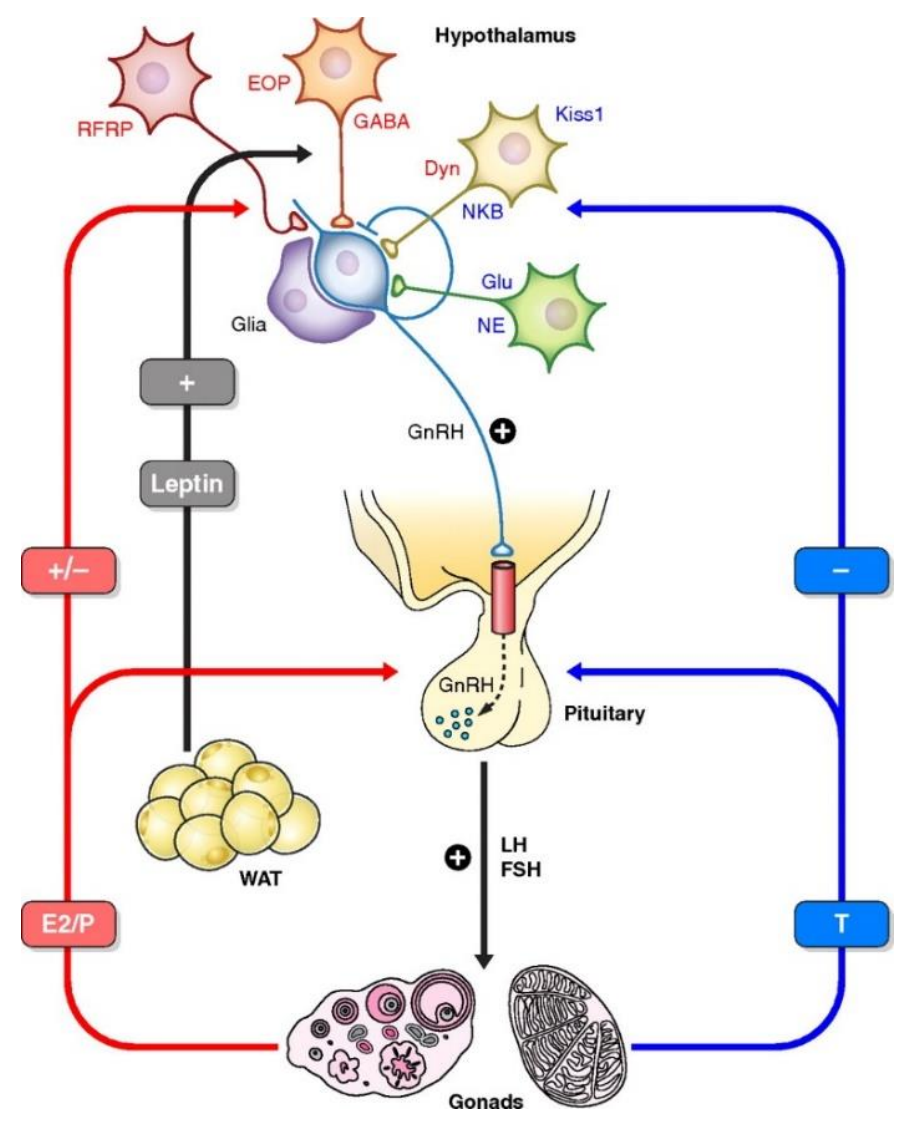

Figura 7. Regulación del eje Hipotálamo - Hipófisis - Gónada (HHG). En el hipotálamo la estimulación de las neuronas GnRH genera la liberación de este neuropéptido al sistema portahipofisiario y llega a los gonadotropos para estimular la liberación de gonadotropinas (FSH y LH), que viajan por el torrente sanguíneo hacia las gónadas (ovario o testículo) para estimular la síntesis y liberación de esteroides gonadales. Regulándose este proceso mediante una retroalimentación negativa (Pinilla et al., 2012). 


\section{Reproducción en la hembra}

En las hembras, el ciclo estral se define como el periodo de tiempo comprendido entre la aparición de un estro y el comienzo del siguiente, o bien, el intervalo de tiempo comprendido entre dos ovulaciones. El ciclo estral en la cabra tiene una duración promedio de 21 días. Durante los primeros días del ciclo se libera la FSH de la hipófisis, la cual estimula en el ovario el crecimiento y maduración folicular, con la consecuente liberación de estradiol hacia el torrente sanguíneo. El estradiol estimula en el hipotálamo la liberación de GnRH y en la adenohipófisis aumenta la sensibilidad de los gonadotropos a la $\mathrm{GnRH}$. Estos efectos causan la liberación de grandes cantidades de LH. De esta forma, el aumento de estradiol en el torrente sanguíneo tiene un efecto de retroalimentación positiva en el AVPV, lo que induce la liberación de GnRH y en consecuencia la oleada preovulatoria del pico de LH inductor de la ovulación en las primeras horas del estro (Smith y Jennes, 2001). Asimismo, el estradiol genera cambios morfológicos y fisiológicos en el tracto genital y estimula además la expresión de la conducta femenina durante el estro. . Después de la ovulación, las células foliculares se modifican y forman el cuerpo lúteo, que produce progesterona; esta hormona actúa a nivel del hipotálamo inhibiendo la secreción de $\mathrm{GnRH}$. Si no hay gestación, el cuerpo lúteo alcanza su máxima talla entre el día 11 y el día 14 después del estro (Bauernfeind y Holtz, 1990) e inicia su regresión como resultado de la producción de prostaglandinas en el útero. Debido a la regresión del cuerpo lúteo, el nivel de progesterona disminuye permitiendo que el hipotálamo sintetice y libere nuevamente $\mathrm{GnRH}$, reiniciando el ciclo (Figura 8). Si hay gestación, el cuerpo lúteo permanece y continúa secretando progesterona hasta el final de la preñez (Hernández y Zarco, 1998). 


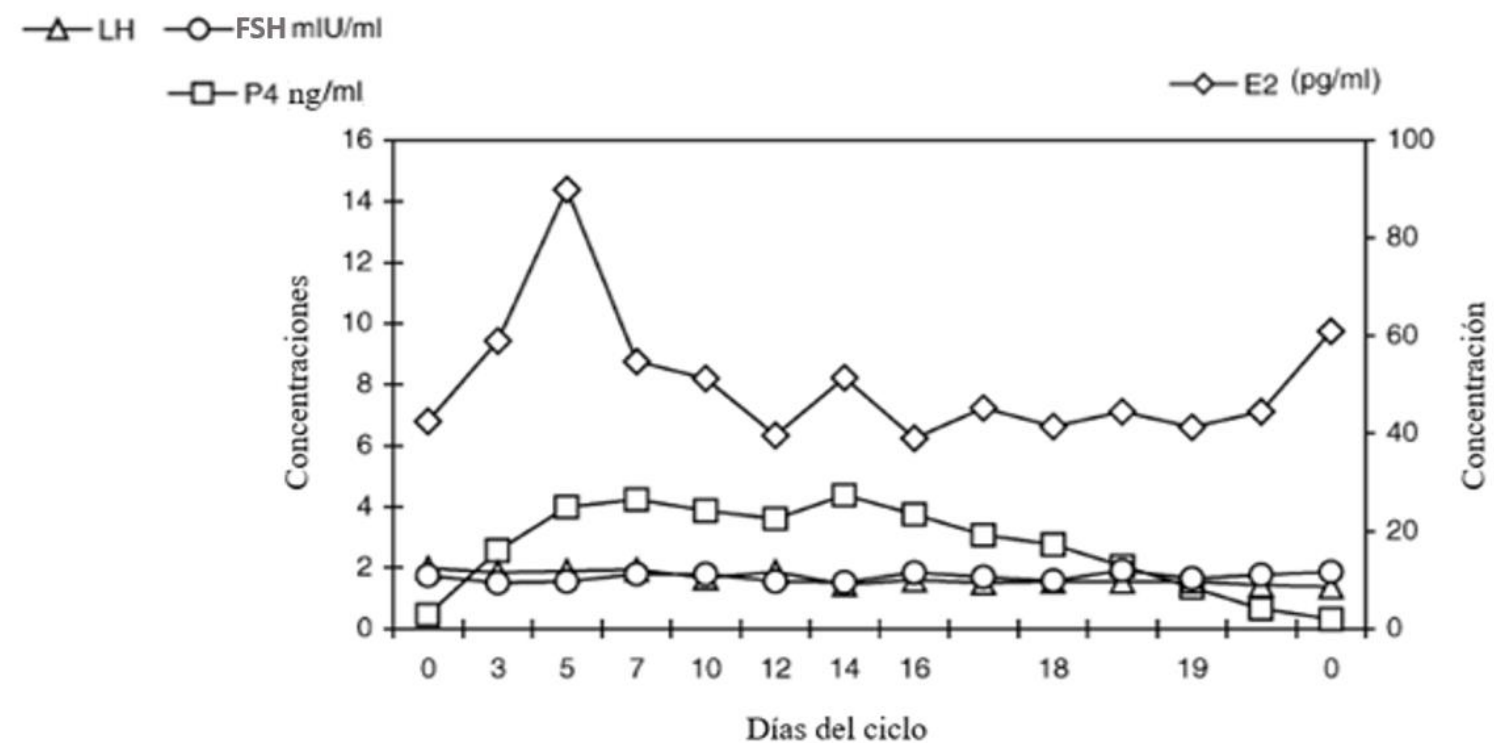

Figura 8. Cambios en la concentración de progesterona (P4, $\mathrm{ng} / \mathrm{mL})$, estradiol $(E 2, \mathrm{pg} / \mathrm{mL}), \mathrm{LH}$ y FSH (mIU/mL) durante el periodo de 21 días del ciclo estral en la cabra (modificado de Gaafar et al., 2005)

\section{Comportamiento reproductivo de la hembra}

La expresión de la conducta reproductiva depende tanto de factores externos, tales como el entorno social, como internos, tales como los niveles de hormonas esteroides sexuales. Aunque no se conocen con exactitud los mecanismos neurales que controlan la conducta reproductiva en las cabras hembras, en las hembras de mamíferos se reconocen estructuras centrales involucradas en este proceso. En la figura 9 se observa un esquema del control neuroendocrino de la conducta sexual en la hembra. El AVPV, el VMH y el MPOA son las estructuras hipotalámicas que regulan la expresión de la conducta sexual de la hembra (Graham y Pfaus, 2010). La conducta sexual femenina se dispara mediante estímulos cutáneos, olfativos y visuales, se facilita por la acción estrogénica en las neuronas del VMH y se manifiesta por contracciones de los músculos posteriores. El AVPV contiene una gran cantidad de neuronas que expresan receptores de estrógenos y progesterona y además proyectan 
directamente sobre las neuronas $\mathrm{GnRH}$ e influyen en la secreción de $\mathrm{LH}$ en la adenohipófisis (Sakamoto, 2012). El MPOA también es importante para la expresión de las conductas precopulatorias (Graham y Pfaus, 2010).

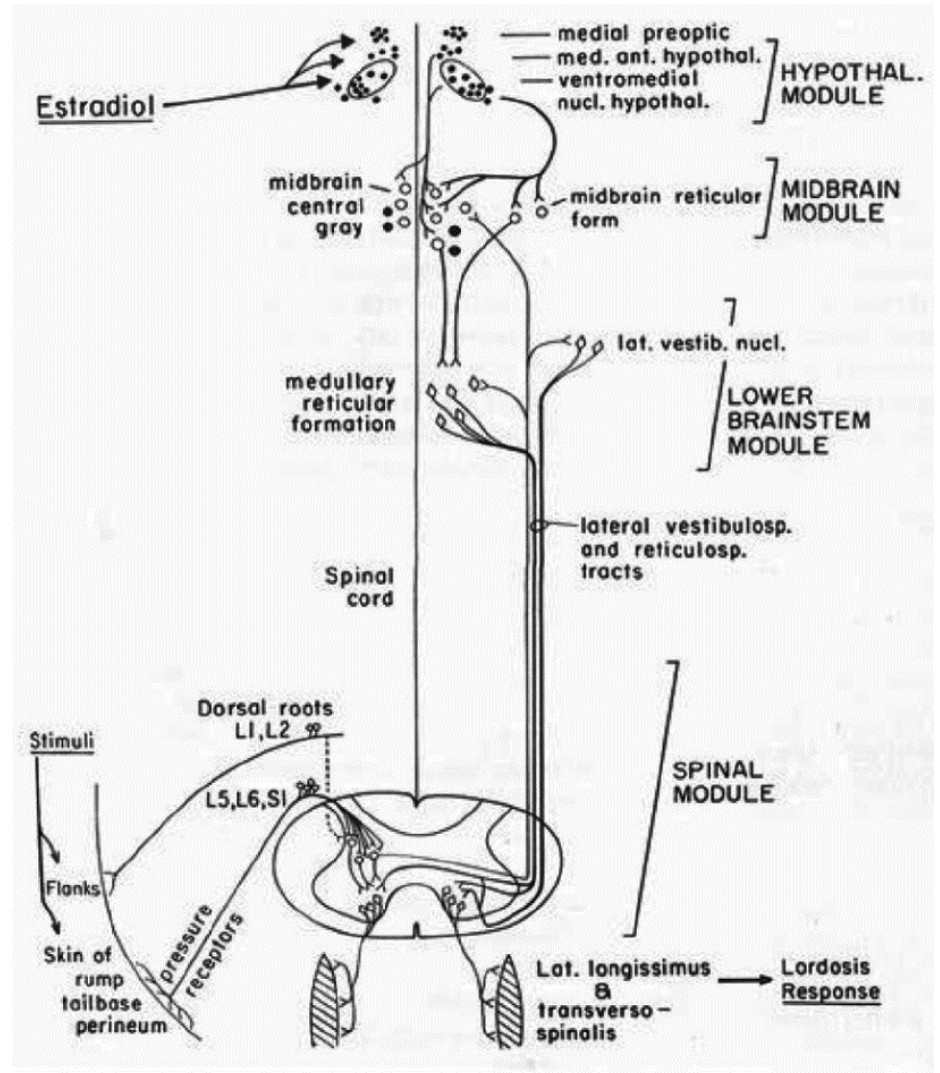

Figura 9. Vías neurales que controlan la expresión de la conducta sexual femenina (Shelley et al, 2007)

En la cabra hembra, la conducta estral incluye dos fases: la Apetitiva y la consumatoria (Fabre Nys, 2000), también conocidas como proceptividad y receptividad. La proceptividad es una fase de búsqueda y estimulación hacia el macho; la hembra orina con frecuencia además de mostrarse inquieta ante la presencia del macho, al término de esta fase e inicio de la siguiente, la hembra hace movimientos rápidos de la cola (Abanicamiento) y puede presentarse secreción de flujo a través de la vulva. La receptividad es la expresión del reflejo de inmovilización o "quietud" en respuesta a la monta del macho, al término de esta fase, después de que le macho 
eyacula, la hembra adopta una posición por unos segundos como si fuera a orinar. Varios autores han descrito la duración de la receptividad, dependiendo de la raza la duración va de las 12 a las 72 horas (Llewelyn et al., 1993, Okada et al., 1996; Fabre Nys, 2000; Fatet et al., 2011)

\section{Reproducción en el macho}

En el macho, La GnRH es liberada desde el MPOA al sistema porta-hipofisiario, a través del cual llega hasta los gonadotropos de la adenohipófisis donde induce la síntesis y la liberación de FSH y LH. A través de la circulación sanguínea, las gonadotropinas son transportadas hasta los testículos. La FSH estimula a las células de Sertoli la síntesis y secreción de nutrientes para mantener a las células germinales durante el proceso de la espermatogénesis. En este proceso también participan la testosterona y la proteína de unión a testosterona (ABP), misma que es sintetizada por las células de Sertoli. Estas células secretan además Activina, la cual estimula la liberación de FSH e Inhibina, que inhibe la liberación de FSH desde la adenohipófisis. Por su parte, la LH estimula a las células de Leydig, las cuales se localizan entre los

túbulos seminífero y bajo la estimulación de LH inician la síntesis y secreción de testosterona (Bustos y Torres, 2012). Los altos niveles de testosterona inhiben la secreción de LH en la adenohipófisis al igual que en hipotálamo inhiben la liberación de GnRH por un mecanismo de retroalimentación negativa. La testosterona también es necesaria para la expresión del comportamiento sexual masculino normal y la función testicular. Debido a la reproducción estacional de los caprinos, el control hormonal se modifica a lo largo del año. En los días cortos se activa la función reproductiva por efecto de la melatonina y en los días largos la liberación de $\mathrm{GnRH}$ se inhibe, lo que se traduce en una disminución en la liberación de LH y la subsecuente baja secreción de testosterona. Durante este período el tamaño testicular, la producción de espermatozoides y el comportamiento sexual se reducen. Así, durante los períodos de días cortos, la función reproductiva del macho se inhibe debido a las bajas concentraciones de testosterona. 


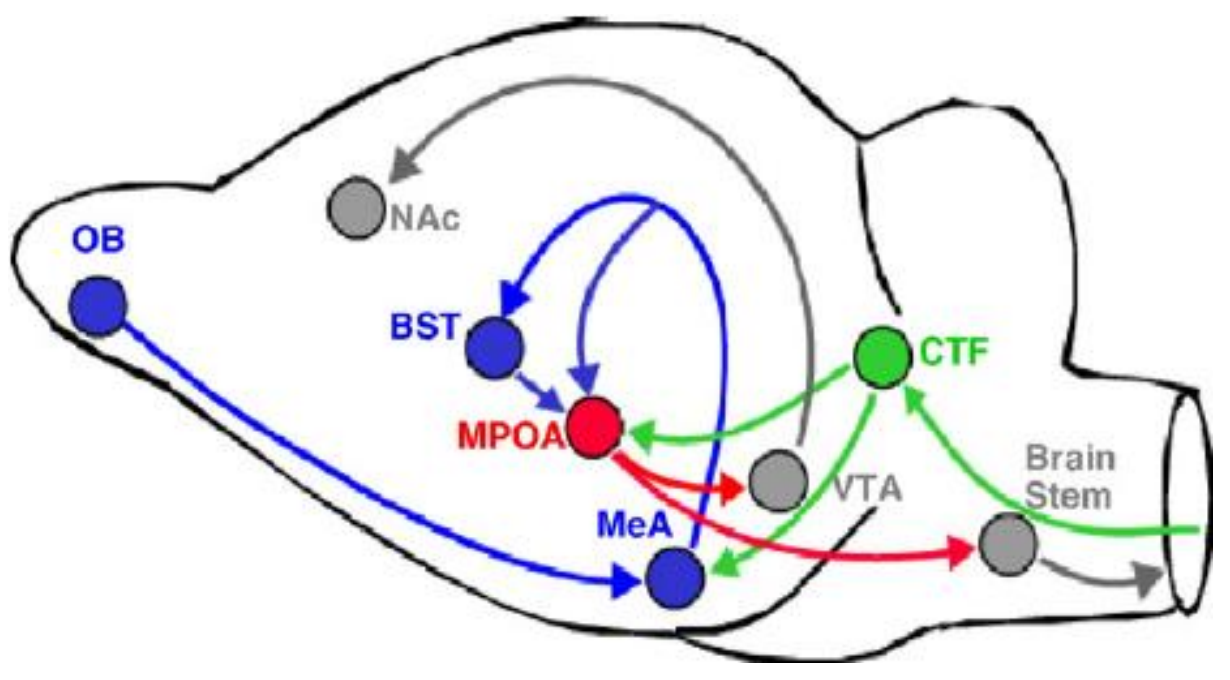

Figura 10. Circuitos neuronales que regulan la conducta sexual masculina. El área preóptica media (MPOA) recibe entradas directas e indirectas de áreas cerebrales importantes para la integración de información sexualmente relevante. La estimulación olfativa llega al bulbo olfatorio (OB), que proyecta hacia la amígdala medial (MeA), la cual envía la información al núcleo de la estría terminal (BST) y el MPOA. EI MPOA y la MeA reciben información somatosensorial vía el campo central tegmental (CTF). EI MPOA proyecta al área ventral tegmental (VTA) y el tallo cerebral (BS) hacia la médula espinal y nervios motores. (Hull y Domínguez, 2006).

\section{Comportamiento reproductivo del macho}

EI MPOA es una de las estructuras cerebrales más importantes involucradas en la regulación de la conducta sexual masculina, la cual presenta patrones motores como son la monta, la intromisión y la eyaculación (Coolen et al., 2004, Domínguez y Hull 2005, Sakamoto, 2012. Figura 10). La testosterona actúa sobre el MPOA para facilitar la expresión del comportamiento sexual a través de la aromatización de andrógenos de la misma manera como se ha observado en roedores (Sakamoto, 2012). Además de la información hormonal, el área preóptica recibe información sensorial del órgano vomeronasal y genitales a través de la amígdala, induciendo reflejos genitales y patrones copulatorios (Katz et al., 1988, Domínguez et al., 2001, Orihuela, 2014). 
En el macho, la expresión de la conducta reproductiva consiste en dos fases al igual que en la hembra: Apetitiva y consumatoria. Durante la fase apetitiva el macho adopta una postura alargando la cabeza como extensión de la espalda para identificar alguna hembra receptiva, continua con una etapa de identificación olfativa oliendo el área anogenital de la hembra, si ésta orina, es seguido por una expresión facial particular, el labio superior curvado, llamado "Flehmen". Si la hembra acepta las primeras aproximaciones del macho, pasa a la fase consumatoria donde da golpes suaves a la hembra con la cabeza y los flancos anteriores, haciendo una emisión de balido característico de cortejo y realiza intentos de apareamiento, hasta que se da la monta con la erección e intromisión del pene, movimientos pélvicos rápidos y finalmente la eyaculación que se caracteriza por la contratación brusca de los miembros anteriores, también conocido como "golpe de riñón" (Figura 11) (Fabre Nys, 2000).

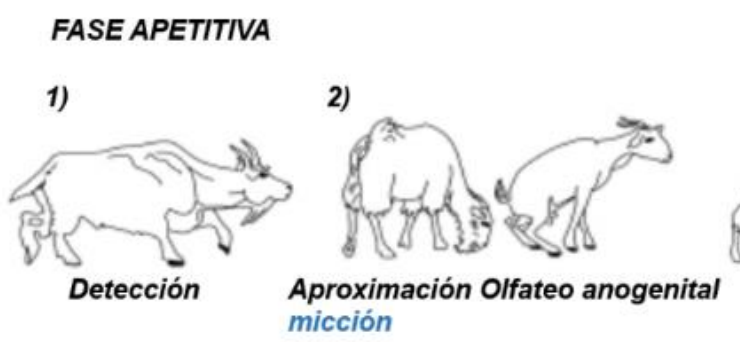

FASE CONSUMATORIA

5)

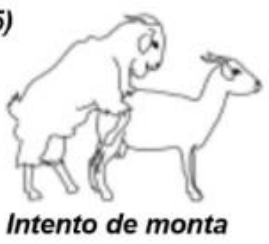

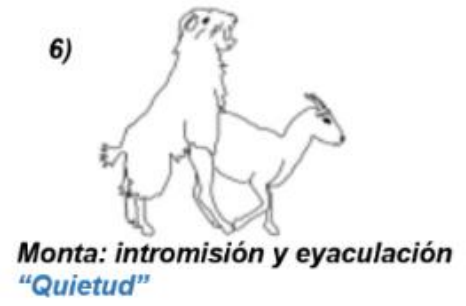

7)

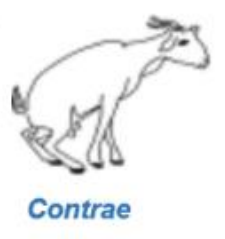

Mov.Cola, se mantiene cerca
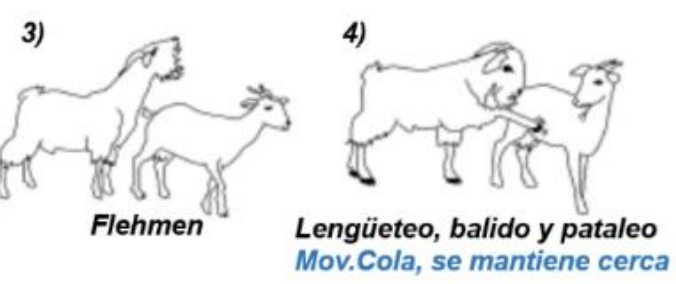

Figura 11. Elementos del comportamiento reproductivo de hembras y machos (Modificado de Fabre Nys, 2000) 
Para la mayoría de los mamíferos, la perpetuación de la especie constituye uno de los objetivos esenciales de la reproducción. Desde el punto de vista económico, la reproducción de las especies domésticas es esencial para la rentabilidad en cualquier sistema de producción. Por esta razón, es importante procurar que los animales domésticos se encuentren en buenas condiciones ambientales y de manejo que permitan mantener un sistema de producción exitoso. Para ello, es necesario evitar en lo posible situaciones estresantes que puedan afectar su producción y reproducción. La activación del eje adrenal en respuesta a situaciones estresantes afecta de manera significativa el funcionamiento reproductivo en varias especies domésticas (Álvarez, 2008). Prácticas como el transporte, el hacinamiento, el manejo o las condiciones ambientales son factores estresantes que pueden inhibir al eje gonadal.

\section{Fisiología del estrés}

El estrés es la respuesta de un organismo en el cual, las demandas ambientales exceden la capacidad reguladora natural del organismo frente a estímulos (estresores) que son impredecibles e incontrolables (Koolhaas et al., 2011). El sistema de respuesta al estrés está comprendido por la activación de dos sistemas: el eje simpático-adrenomedular (SNS) y el eje hipotálamo-hipofisis-adrenal (HHA) (Tilbrook et al., 2000). La activación del SNS y la medula adrenal involucra la liberación de catecolaminas (adrenalina y noradrenalina) que ayudan a los individuos a movilizar rápidamente fuentes de energía para cubrir los requerimientos metabólicos para una reacción de huida o lucha (Dantzer y Mormede, 1983). Las catecolaminas actúan en conjunto con los glucocorticoides para aumentar la disponibilidad de glucosa a través de su acción glucogenolítica (Dukes, 2004). Además de la movilización de reservas de energía, las catecolaminas disminuyen la liberación de gonadotropinas y pueden afectar la reproducción (Álvarez 2008). Los sistemas de producción caprina en las zonas áridas se desarrollan en su mayoría en condiciones desfavorables de alimentación, restricción de agua, hacinamiento, temperaturas extremas y manejo deficiente, que a su vez son condiciones consideradas como factores estresantes para 
los animales. La cabra ha sido considerada una de las especies con mayor adaptación a dichas condiciones en comparación con otras especies domésticas debido a su mejor tolerancia y rendimiento a ese tipo de ambientes. (Silanikove, 2000) describió que la capacidad de adaptación de la cabra es multifactorial, es una especie con menos masa corporal y con capacidad de disminuir sus necesidades metabólicas de mantenimiento y agua, en zonas donde las temperaturas son muy elevadas y el acceso al agua es muy restringido. Además es una de las especies con un comportamiento de pastoreo hábil y un eficiente sistema digestivo que les permite alcanzar la ingesta y utilización de alimentos máxima. Sin embargo, esto no significa que su organismo no responda ante las diferentes situaciones estresantes.

\section{Activación del eje HHA}

Este eje está representado por la población de neuronas secretoras de la hormona liberadora de corticotropina $(\mathrm{CRH})$ y neuronas secretoras de la arginina vasopresina (AVP) en núcleo Paraventricular (PVN) del hipotálamo. La secreción de estas dos hormonas, estimula la liberación de la hormona adrenocorticorticotropina (ACTH) de la hipófisis y viaja a través del torrente sanguíneo llega a la corteza de la glándula adrenal, donde estimula la síntesis y secreción de glucocorticoides (cortisol y corticosterona). El cortisol, glucocorticoide de mayor importancia en los rumiantes, participa en el metabolismo de proteínas, carbohidratos y grasas (Guyton et al., 2006). El eje hipotálamo-hipófisis-adrenal (HHA) ejerce profundos efectos inhibidores sobre el eje reproductivo a través de la secreción de la $\mathrm{CRH}$ y de los glucocorticoides (Mastorakos et al., 2006).

\section{Factores que pueden afectar la reproducción}

En los climas cálidos, la temperatura ambiente, la alta radiación solar, la velocidad del viento, humedad y restricción de agua son los principales factores ambientales que imponen estrés en los animales (Finch, 1986). Se activa entonces una respuesta de adaptación como un intento de restablecer el equilibrio dinámico en el organismo 
(Rostagno, 2010). El estrés causa inhibición de diversos aspectos reproductivos, tales como la secreción de gonadotropinas, hormonas sexuales, así como el comportamiento reproductivo (Pierce et al., 2008). La activación del eje adrenal puede inhibir directamente al eje gonadal a diferentes niveles: inhiben la liberación de $\mathrm{GnRH}$ por efecto directo de la $\mathrm{CRH}$ en el hipotálamo, disminuyen la sensibilidad de los gonadotropos a la $\mathrm{GnRH}$ por efecto de los glucocorticoides, disminuyendo así la secreción de la LH en la hipófisis, a nivel gonadal disminuye la síntesis y liberación de esteroides sexuales (Handa y Weiser, 2014) (Figura 12). Las respuestas a los factores de estrés a corto y largo plazo pueden ser diferentes según el tipo de estresor. Además de afectar negativamente la reproducción, también genera que los animales tengan dificultades para hacer frente a su entorno, causando problemas productivos como disminución del crecimiento y la baja producción de leche, disminuyendo el bienestar social y aumentando el riesgo de enfermedades y la mortalidad (Silanikove, 2000).

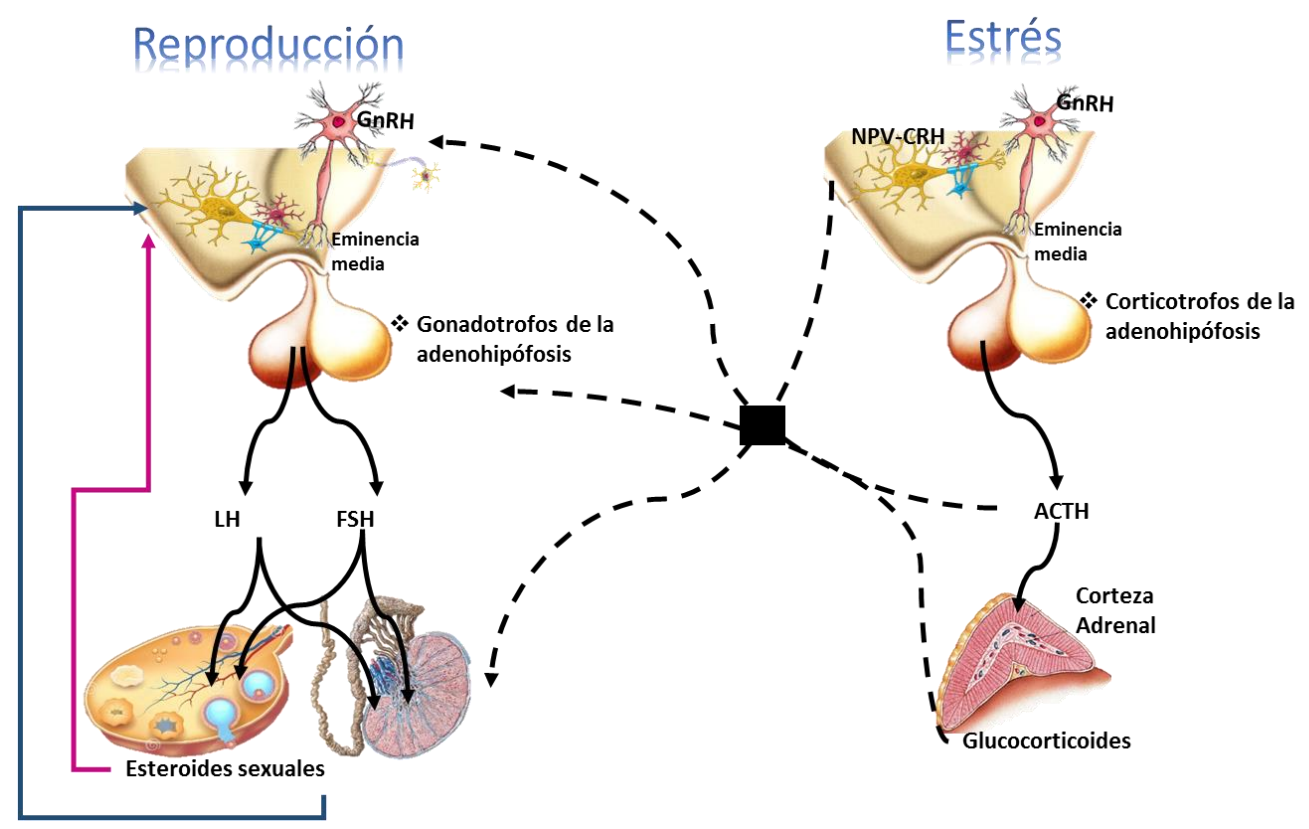

Figura 12. La activación del eje HHA puede afectar al eje HHG a diferentes niveles: inhibiendo la liberación de $\mathrm{GnRH}$, la sensibilidad de los gonadotropos a la GnRH o la síntesis de esteroides gonadales. Además, el estrés puede afectar la retroalimentación negativa de los esteroides gonadales en hipotálamo e hipófisis (Adaptado de Chrousos et al. 1998) 


\section{ANTECEDENTES}

\section{Estrés y producción animal}

La activación del eje adrenal y el consiguiente aumento de la concentración de cortisol en plasma son las respuestas más prominentes de un animal a las condiciones de estrés (Silanikove, 2000). Los principales factores de estrés en los sistemas de producción animal incluyen el bajo consumo de agua y/o alimento, el transporte, las temperaturas extremas, el hacinamiento y la manipulación. Existen varios indicadores fisiológicos que permiten evaluar la respuesta de estrés, uno de ellos es el cortisol sérico o plasmático que ha sido el más utilizado para evaluar el estrés en cabras (Kannan et al., 2003). También se han utilizado como indicadores de estrés las catecolaminas en la orina y/o de sus metabolitos, el ácido láctico, las enzimas séricas, la glucosa en sangre, las alteraciones en la frecuencia respiratoria o cardiaca y el recuento de células somáticas en la leche (Alejandro, 2014). A continuación se describen los principales factores de estrés y sus efectos en la producción animal.

\section{Interacción social y Hacinamiento}

En los sistemas productivos, el hacinamiento es un factor de estrés que se demuestra con el aumento en los niveles de cortisol y conductas de agresión entre los animales, que obliga a cada individuo a interactuar, competir y no tener oportunidad de escapar del atacante, por tanto esa interacción social de agresión genera miedo cuando escapar ya no es una opción (Vas et al., 2013). La interacción y competencia es provocada por el acceso diferencial a recursos, ya sea por espacio, alimento, agua o pareja. Además desencadena una respuesta fisiológica de estrés, inhibe la respuesta inmune y disminuye el desempeño reproductivo de los individuos (Gupta et al., 2005).

El hacinamiento puede generar desestabilización de la jerarquía social y conllevar un aumento en la agresividad (Andersen et al., 2008). La alta frecuencia de las interacciones agresivas puede provocar la disminución de la tasa de ingesta de 
alimento y disminución del crecimiento corporal, y por tanto afectar el éxito reproductivo (Andersen et al., 2008). El cambio en la composición de la jerarquía social modifica también la reproducción. En un estudio realizado en vacas, se observó que las vacas que aumentaron su estatus social fueron más fértiles, tuvieron mayor duración del estro y mejores cifras de producción de leche que las vacas subordinadas (Dobson y Smith, 2000). Por lo tanto la dominancia social reduce tanto el número de vacas en celo como la duración del estro (Landaeta-Hernández et al., 2004).

\section{Transporte y manipulación}

El transporte es otro manejo habitual al que son sometidos los animales de producción y se considera, junto con la manipulación, uno de los estresores más importantes (Grandin, 1997). En cabras, el estrés por transporte provoca, pérdida de peso corporal además de los cambios endocrinos característicos de la respuesta de estrés (aumento en los niveles de glucosa y cortisol) (Kannan et al., 2000, 2003). Existen trabajos que describen los cambios fisiológicos provocados por el transporte en animales. En el ciervo se ha descrito que durante el transporte disminuye su frecuencia cardiaca (Waas et al., 1999) y la concentración de cortisol se duplica a lo largo de dos horas de transporte (Waas et al., 1997). En animales domésticos como la cabra y la oveja el estudio de los efectos del transporte son principalmente acerca de la disminución en la calidad de la carne, las respuestas fisiológicas (aumento de la temperatura, la frecuencia cardiaca y la frecuencia respiratoria) e inmunológicas (Zhong et al., 2011), así como los índices de mortalidad (Malena et al., 2007). Sin embargo, el efecto de este estresor sobre la reproducción se ha estudiado poco, debido a que el transporte de animales productivos es principalmente hacia los mataderos o rastros.

El hecho de que los factores que causan estrés sean perjudiciales para una función tan importante como es la reproducción, hace que el estudio de los efectos del estrés en la reproducción de los animales de importancia económica sea un punto muy importante, esto con la finalidad de minimizar el estrés en la medida de lo posible para poder optimizar la producción animal (Dobson et al., 2001). 


\section{Bajo consumo de agua y/o alimento}

El agua es un requisito absoluto para el ganado, y la ausencia de este elemento puede ser un factor limitante crítico en la fisiología de los animales y su productividad. En las zonas áridas y semiáridas el clima que prevalece durante los meses de verano es muy caliente, los pastos disponibles son secos y fibrosos, y hay un acceso limitado al agua (Alamer, 2010). Cuando los animales se encuentran en condiciones de restricción de agua, bajan progresivamente el consumo de alimento (Abdelatif y Ahmed, 1994). En ovejas, el movimiento de la mandíbula se reduce drásticamente, dando como resultado el deterioro de la rumia (Aganga et al., 1989). El agua es esencial para la digestión en la eliminación de residuos no digeridos y excreción de los productos de desecho del metabolismo, por esta razón varios autores relacionan la ingesta de agua y alimento en rumiantes (Steiger et al., 2001; Abioja et al., 2010). En cabras, el bajo consumo de agua durante la temporada seca afecta la frecuencia cardiaca, la frecuencia respiratoria y la producción de leche (Adogla-Bessa y Aganga, 2000). Además, la disminución en el consumo de alimento disminuye la ganancia de peso y el crecimiento (Abdelatif y Ahmed, 1994). En las cabras, es necesario un mayor consumo de alimento antes del apareamiento durante la época reproductiva para mejorar las tasas de ovulación y de concepción (Mani et al., 1994). En cabras que se encuentran en regiones hostiles y con baja disponibilidad de alimento se ha observado la presencia de anestros prolongados, períodos anovulatorios, reducción de la fertilidad y la prolificidad (Fatet et al., 2011). En otros rumiantes como las vacas y las ovejas, el bajo consumo de agua se ve reflejado en la baja producción de leche, debido a las grandes distancias que recorre el animal durante el pastoreo en sistemas extensivos, así como a la baja disponibilidad de nutrientes en la dieta, por lo que es importante que los animales tengan agua disponible a libre acceso (Avalos et al., 2009).

\section{Calor}

La cabra se ha considerado como una de las especies más tolerantes al estrés por calor en comparación con otras especies domésticas como las vacas o las ovejas, 
debido a su mayor tasa de sudoración y su menor peso corporal, características que le permiten una mayor disipación de calor (Salama et al., 2014). Se sabe que el estrés por calor en las cabras tiene efectos negativos sobre las funciones termorreguladoras a temperaturas mayores a $40^{\circ} \mathrm{C}$, ya que aumentan la frecuencia respiratoria y la temperatura rectal (Hamzaoui et al., 2013). Asimismo, a temperaturas ambientales altas disminuye el consumo de alimento y por lo tanto el peso corporal, ya que el alimento es una fuente importante de producción de calor en los rumiantes (Kadzere et al., 2002). Otros autores, sin embargo, no han observado cambios en la frecuencia cardiaca, la frecuencia respiratoria, la temperatura rectal o los niveles de glucosa en sangre en cabras expuestas a estrés por calor, a pesar de la disminución en el consumo de alimento(Salama et al., 2014). A nivel reproductivo, el comportamiento sexual y la fertilidad en las hembras son los principales eventos afectados negativamente por el estrés. En las vacas, el estrés por calor disminuye las tasas de concepción dramáticamente durante el verano, debido a que se prolonga la fase lútea del ciclo estral, en comparación con otras temporadas del año (Sakatani, 2012). Además, la secreción de la FSH también se inhibe, afectando así el reclutamiento, la selección y la dominancia folicular (Wolfenson et al., 1995). En las ovejas, el estrés por calor reduce la fertilidad al interferir con el desarrollo y el crecimiento folicular, alarga además el ciclo estral, debido a la disminución de la secreción pulsátil de LH (Breen et al., 2005). . Esto redunda en ovulaciones tardías y reducción en la producción de 17ßestradiol por los folículos en crecimiento, ya que la LH es el paso limitante para la producción de estrógenos (Dobson y Smith, 2000). Asimismo, la conducta sexual se inhibe (Breen et al., 2005). 


\section{JUSTIFICACION}

Los sistemas de producción caprina en la Mixteca enfrentan serios problemas, la deficiencia en las instalaciones genera hacinamiento y limita el acceso a los recursos naturales como lo es el agua. Estos factores estresantes pueden estar afectando la reproducción y la producción caprina. Por lo anterior, es importante realizar estudios que brinden información acerca de las alteraciones que el estrés causa en la reproducción. Este conocimiento permitirá proponer estrategias, como podría ser el enriquecimiento ambiental, tendientes a mejorar la reproducción en dichos sistemas de producción animal.

\section{OBJETIVOS}

\section{GENERAL}

Evaluar el efecto del estrés por hacinamiento y restricción de agua en parámetros reproductivos de cabras criollas de la Región Mixteca Oaxaqueña

\section{ESPECÍFICOS}

- Determinar las alteraciones que causa el estrés en el ciclo estral y la actividad del eje adrenal

- Evaluar la actividad endócrina del ovario y la conducta reproductiva en hembras estresadas crónicamente.

- Evaluar los efectos del estrés ambiental crónico sobre la actividad endócrina del testículo y la conducta reproductiva en machos. 


\section{PLANTEAMIENTO DEL PROBLEMA}

El éxito reproductivo de los animales domésticos, es uno de los factores que determinan la rentabilidad de los sistemas de producción pecuarios. El bienestar animal permite que se exprese todo el potencial productivo, teniendo en cuenta que el bienestar va ligado a producción. El estrés desencadena una serie de respuestas neuroendocrinas que pueden afectar la eficiencia reproductiva y por lo tanto provocar disminución en la producción animal. Los factores estresantes más frecuentes en los sistemas de producción caprina en la Mixteca son los factores medio-ambientales como las altas temperaturas, la altitud, la aridez de los terrenos, la condición del acceso al agua, que generalmente es restringido, y otro importante factor de estrés es el hacinamiento.

Es importante realizar estudios que permitan determinar la afectación reproductiva por causa del estrés en las cabras, mediante métodos ya utilizados como la evaluación de los niveles plasmáticos de cortisol y hormonas esteroides, así como la evaluación de la conducta sexual, que es esencial para el apareamiento en condiciones naturales.

Hasta la fecha no se ha reportado con certeza el grado de afectación que los factores ambientales estresantes tienen sobre la reproducción de las cabras. El conocimiento de esta información es necesario para que se puedan proponer estrategias que aminoren los efectos del estrés en los sistemas de producción caprina y mejorar así su producción y reproducción.

\section{HIPÓTESIS}

Si el estrés es un factor que influye negativamente sobre la reproducción, entonces la expresión de la conducta sexual y el nivel de hormonas reproductivas se verán disminuidas en cabras criollas de la Mixteca Oaxaqueña que se encuentran en condiciones de estrés ambiental y social. 


\section{MATERIAL Y MÉTODOS}

\section{Ubicación del lugar de estudio}

El estudio se realizó en el municipio de Cosoltepec, que se localiza en la parte noroeste del estado de Oaxaca, en la región de la Mixteca, en las coordenadas: Iongitud $97^{\circ} 47^{\prime} 25^{\prime \prime} \mathrm{O}$, latitud $18^{\circ} 08^{\prime} 30^{\prime \prime} \mathrm{N}$ y con una altitud de 1,849 metros sobre el nivel del mar. Limita al norte con el municipio de Chazumba; al sur con el municipio de San Pedro y San Pablo Tequixtepec; al oriente con el municipio de Chazumba; al poniente con municipio de Petlalcingo y Tonahuixtla, Puebla. El clima es templado seco y la región es montañosa y árida (INAFED, 2010).

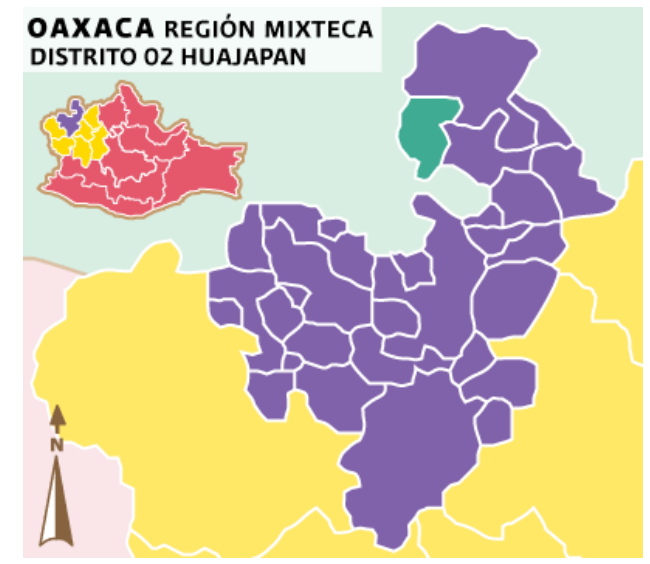

\section{Selección de animales y su manejo}

Se utilizaron cabras criollas (Capra hircus) de aproximadamente uno a dos años de edad y un peso promedio de $38 \pm 1.5 \mathrm{~kg}$ de rebaños ubicados en la comunidad, 10 hembras, 7 machos y un semental se asignaron al grupo control (espacio $2 \mathrm{~m}^{2} /$ cabra y suministro de agua diaria dentro del corral y durante el pastoreo) y 10 hembras, 9 machos y un semental al grupo de estrés (condiciones a las que están habituadas: espacio $40 \mathrm{~cm}^{2} /$ cabra sin suministro de agua en el corral, solo la ingerían durante el pastoreo). Se mantuvieron en esas condiciones por seis meses (Septiembre 2015Febrero 2016). Cada grupo se mantuvo en un corral, ambos grupos estaban separados entre sí por una distancia de 1200 metros, con el objetivo de evitar la percepción visual y olfativa entre los grupos. Durante todo el experimento, los animales fueron alimentados en pastoreo con una duración de $6 \pm 1$ horas al día. Cada día por la mañana, los animales salían al pastoreo y regresaban por la tarde a su respectivo corral. 


\section{Condiciones Ambientales}

Las condiciones ambientales se midieron con una estación meteorológica portátil. La temperatura mínima registrada en el periodo en el que se realizó el experimento fue de $6 \stackrel{\circ}{\circ}$ y la máxima de $42.8^{\circ} \mathrm{C}$. La velocidad del viento osciló entre los 5 y los $34 \mathrm{Km} / \mathrm{h}$. La precipitación promedio fue de $3.9 \mathrm{~mm}$ y la cantidad de horas luz (fotoperiodo) promedio fue de $12.5 \mathrm{~h}$ diarias.

\section{Obtención y procesamiento de las muestras sanguíneas}

Las muestras sanguíneas se obtuvieron por venopunción yugular en tubos Vacutainer de $4.0 \mathrm{~mL}$ sin anticoagulante, con un gel separador activador del coágulo. Cada muestra se etiquetó con la identificación del animal, fecha y número de muestra. Se dejaron una hora a temperatura ambiente y después en refrigeración para la retracción del coágulo, se obtuvo el suero y se colocó en tubos Eppendorf de $2 \mathrm{~mL}$. Al término de cada muestreo, las muestras séricas fueron transportadas y congeladas a $-20 \stackrel{\circ}{ } \mathrm{C}$ hasta su evaluación.

\section{Respuesta de estrés}

\section{Cortisol}

Para evaluar la actividad del eje adrenal en ambos grupos, el 15 de Enero 2016 se colectaron muestras de sangre por un día completo $(24 \mathrm{~h})$ en intervalos de $3 \mathrm{~h}$, obteniéndose en total 7 muestras por animal. Las extracciones sanguíneas fueron realizadas por 4 personas, dos en cada grupo. Una persona sujetaba a los animales y la otra tomaba la muestra en cada uno de los animales. La duración aproximada de este procedimiento fue de 20 minutos en cada muestreo. La concentración de cortisol se determinó mediante el método de ELISA, utilizando un kit comercial marca DRG específico de la hormona (cortisol, EIA-1887) y se trabajó de acuerdo con las especificaciones del proveedor. La ejecución del ensayo incluyó una curva estándar y 
el límite de detección fue de $5.13 \mathrm{ng} / \mathrm{mL}$. Se determinó la absorbancia de cada pocillo a $450 \mathrm{~nm}$ con un lector de placa de microtitulación.

\section{Parámetros reproductivos}

\section{Ciclo estral}

Para la determinación de la duración del ciclo estral, se tomó como el día 0 aquel en el que las hembras presentaban el comportamiento de estro. Y el último día si retornaban nuevamente al estro.

\section{Estradiol y Progesterona}

Las muestras de sangre para la medición de estradiol y progesterona fueron tomadas durante el día 0 , que era el día en que presentaban comportamiento estral y se consideraron dentro de la fase folicular. Otra toma de muestra se realizó en el día 10 posterior a la aparición del estro y se consideró dentro de la fase lútea. Ambas muestras fueron tomadas por la mañana. La concentración de estradiol y progesterona se determinaron mediante el método de ELISA, con ensayos comerciales marca DRG específicos para cada hormona: progesterona (EIA-1561) y estradiol (EIA-2693), las cuales se trabajaron de acuerdo con las especificaciones del proveedor. Cada ejecución incluyó una curva estándar, el límite de detección para estradiol fue de 0.10 $\mathrm{pg} / \mathrm{mL}$ y para progesterona fue de $0.1 \mathrm{ng} / \mathrm{mL}$. Se determinó la absorbancia de cada pocillo a $450 \mathrm{~nm}$ con un lector de placa de microtitulación.

\section{Testosterona}

Las muestras de sangre para la medición de testosterona fueron tomadas en machos y sementales de ambos grupos antes de iniciar la reproducción (Diciembre), y durante la actividad reproductiva (Enero). Las muestras fueron tomadas por la mañana y la concentración de testosterona se determinó mediante el método de ELISA, con un kit comercial marca DRG específico para testosterona (EIA-1559) y se trabajó de acuerdo 
con las especificaciones del proveedor. El ensayo incluyó una curva estándar con un límite de detección de $0.49 \mathrm{ng} / \mathrm{mL}$ y se determinó la absorbancia de cada pocillo a 450 nm con un lector de placa de microtitulación.

\section{Observaciones conductuales}

Para las observaciones del comportamiento reproductivo, los animales fueron identificados individualmente con números pintados en un listón que se les colocó en el cuello. Las observaciones se realizaron por una persona, utilizando una cámara de video por 3 horas en el periodo de mayor actividad por la mañana (09:00 a 12:00 h) a cada uno de los grupos durante todo el experimento, alternando los días de observación a modo de registrar los datos observados en todos los individuos.

Se elaboró un ETOGRAMA para evaluar el comportamiento reproductivo de hembras y machos, determinando si presentaban o no la conducta y asignando una puntuación de acuerdo al número de conductas presentadas, en una escala del 0 al 10 , donde 0 indica que no presentaron ninguna conducta y 10 indica que presentaron todas las conductas. Durante cada sesión se registraron por individuo las siguientes conductas:

-Hembras

a) Fase apetitiva: Movimiento de la cola, micción frecuente, secreción de flujo

b) Fase consumatoria: Quietud, contracción de flancos anteriores (después de la retirada del macho)

-Machos

a) Fase apetitiva: Automarcaje, olfateo anogenital, lengüeteo, Flehmen, pataleo, balido

b) Fase consumatoria: Intentos de monta y monta (intromisión y eyaculación) 
Cada una de las conductas registradas se basó en las conductas descritas por FabreNys, 2000, como se muestra en la figura 11.

\section{Análisis estadístico}

Las concentraciones séricas de estradiol, progesterona y testosterona se analizaron con una prueba de t-Student. El cortisol se analizó mediante un análisis de varianza (ANOVA) para medidas repetidas. El comportamiento reproductivo se analizó con una prueba de chi-cuadrado $\left(X^{2}\right)$ y se realizó una correlación de Pearson entre el comportamiento reproductivo y la concentración de hormonas. Los datos se expresan como la media \pm EEM y se estableció un nivel de significancia de $p<0.05$. 


\section{RESULTADOS}

\section{Hembras}

Cortisol

Las concentraciones séricas de cortisol entre las hembras del grupo control y el grupo de estrés fueron significativamente diferentes $(F=4.502 ; \mathrm{p}<0.05)$; la variación circadiana de esta hormona fluctuó en ambos grupos de manera similar pero a diferentes niveles. En el grupo control la concentración más alta de cortisol fue de 19.6 $\mathrm{ng} / \mathrm{mL}$ y la más baja fue de $6.95 \mathrm{ng} / \mathrm{mL}$. En el grupo de estrés el valor más alto fue de $43.95 \mathrm{ng} / \mathrm{mL}$ y el más bajo fue de $24.83 \mathrm{ng} / \mathrm{mL}$ (Figura 13).

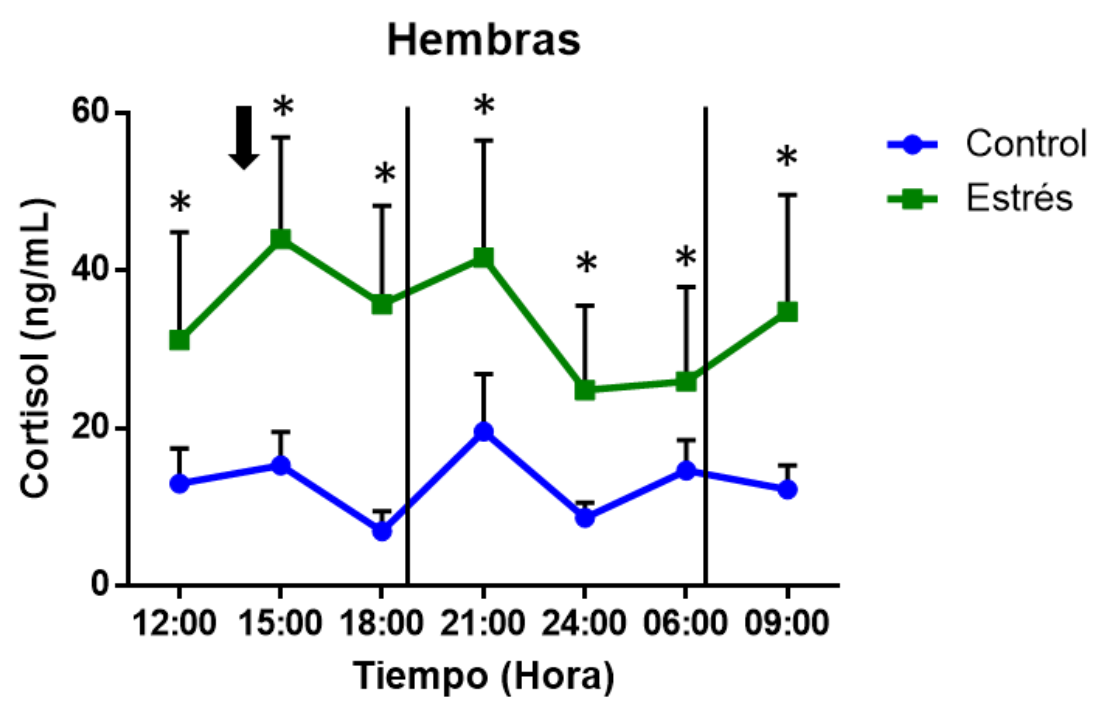

Figura 13. Concentración de cortisol en suero de cabras hembras durante un periodo de $24 \mathrm{~h}$ (media + EEM). La línea azul indica el grupo control y la línea verde el grupo de estrés. La flecha muestra el momento en el que los animales fueron alimentados y las líneas verticales delimitan los periodos del día y la noche. Diferencias significativas entre los grupos en cada hora se indican como ${ }^{*} p<0.05$. 


\section{Parámetros reproductivos}

\section{Ciclo estral}

En el grupo control, la duración del ciclo estral fue de $22.13_{ \pm} 0.44$ días. En el grupo estresado la duración del ciclo fue de $23.1 \pm 0.84$ días. No se encontraron diferencias significativas entre los grupos.

\section{Estradiol}

La concentración sérica de estradiol mostró diferencias significativas en la fase folicular del ciclo estral entre los grupos $(\mathrm{t}=2.441 ; \mathrm{P}<0.05)$. El promedio en el grupo control fue de $60.72 \mathrm{pg} / \mathrm{mL}$ y en el grupo de estrés el promedio fue de $48.03 \mathrm{pg} / \mathrm{mL}$ durante el estro. En la fase lútea no se obtuvieron diferencias significativas entre las hembras de ambos grupos (Figura 14).

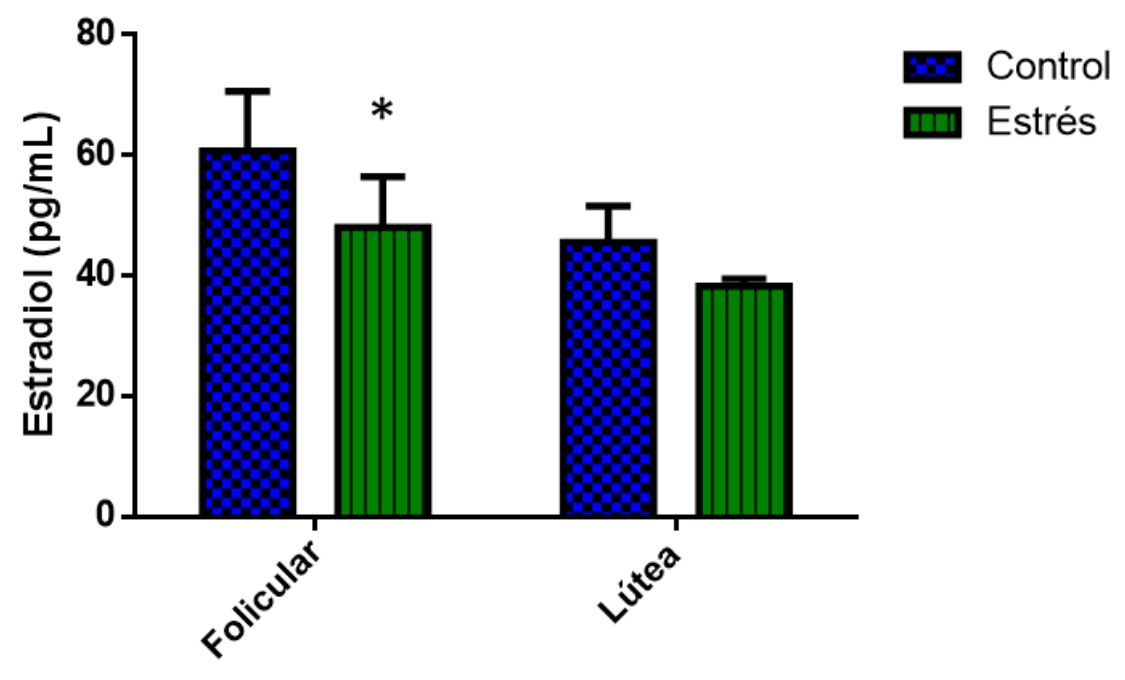

Figura 14. Comparación de la concentración de estradiol en suero del grupo control y el grupo de estrés en las diferentes fases del ciclo estral (Folicular y Lútea) (media + EEM). Diferencias significativas entre los grupos por fase se indican como ${ }^{*} p<0.05$. 


\section{Progesterona}

La concentración de progesterona mostró diferencias significativas durante la fase lútea del ciclo estral entre los grupos $(t=0.788 ; p<0,05)$. Se obtuvo un promedio de 6.59 $\mathrm{ng} / \mathrm{mL}$ en el grupo control y $4.13 \mathrm{ng} / \mathrm{mL}$ en el grupo de estrés. En la fase folicular no se obtuvieron diferencias significativas entre los grupos (Figura 15).

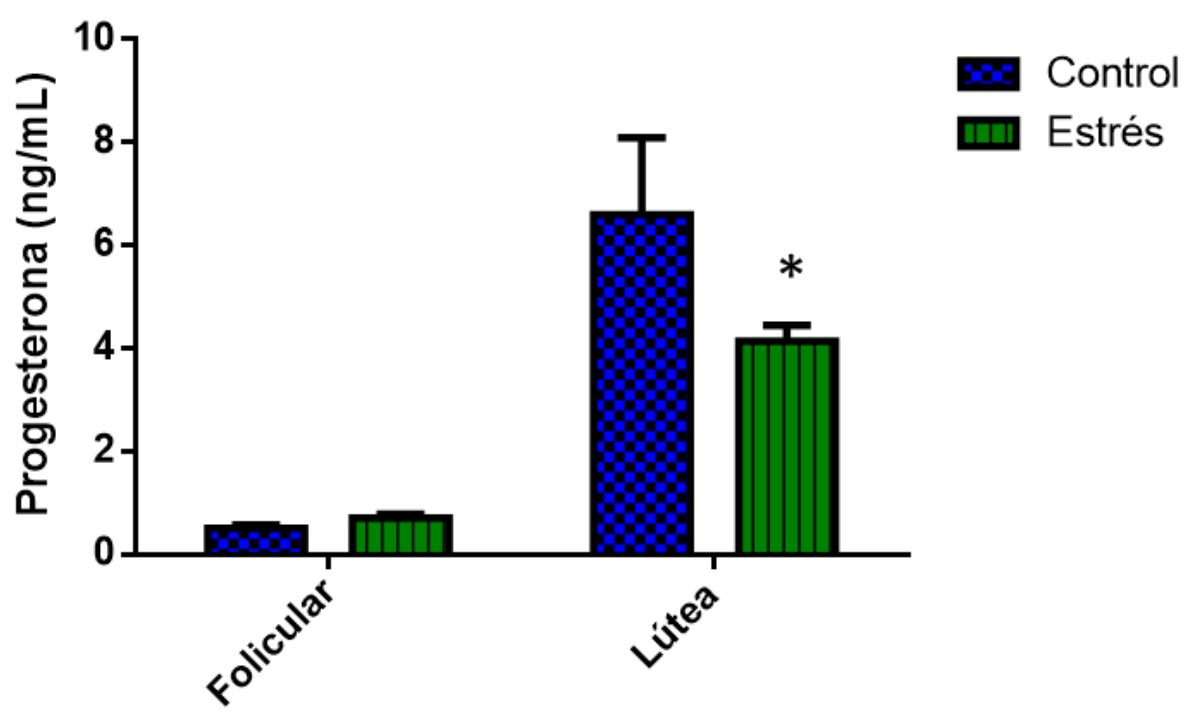

Figura 15. Comparación de la concentración de progesterona en suero del grupo control y el grupo de estrés en las diferentes fases del ciclo estral (Folicular y Lútea) (media + EEM). Diferencias significativas entre los grupos por fase se indican como * $(P<0.05)$. 


\section{Observaciones conductuales}

En la observación del comportamiento reproductivo de las hembras, se obtuvieron diferencias significativas para las conductas de: micción frecuente, secreción de flujo y contracción de los flancos posteriores $(p<0.05)$. En las conductas de movimiento de cola y quietud no existieron diferencias significativas $(p>0.05)$. En la tabla 1 se muestra el porcentaje total de hembras de ambos grupos que presentaron cada una de las conductas.

Tabla 1. Porcentaje de las conductas presentadas entre los grupos de hembras (*) Denota diferencia significativa $(P<0.05)$ entre los grupos cuando las conductas $S \mathbf{I}$ fueron presentadas

\begin{tabular}{|c|c|c|c|c|c|c|}
\hline \multicolumn{7}{|c|}{ Etograma } \\
\hline & \multicolumn{3}{|c|}{ Control } & \multicolumn{3}{|c|}{ Estrés } \\
\hline Conducta & $\%$ SI & $\%$ NO & Total & $\%$ SI & $\%$ NO & Total \\
\hline Mov.cola & 80 & 20 & 100 & 60 & 40 & 100 \\
\hline Micción & 90 & 10 & 100 & $40^{*}$ & 60 & 100 \\
\hline Flujo & 90 & 10 & 100 & $40^{*}$ & 60 & 100 \\
\hline Quietud & 50 & 50 & 100 & 30 & 70 & 100 \\
\hline $\begin{array}{l}\text { Contracción } \\
\text { de flancos } \\
\text { posteriores }\end{array}$ & 90 & 10 & 100 & $50^{*}$ & 50 & 100 \\
\hline
\end{tabular}

Se obtuvo una correlación entre el comportamiento reproductivo de las hembras control con el estradiol en la fase folicular $(r=0.684)$ y la progesterona en la fase lútea $(r=0.743)$. La correlación con el cortisol no fue significativa. En el grupo de estrés, la correlación entre la conducta y el estradiol folicular fue significativa $(r=0.829)$ pero no así en la progesterona lútea. Se obtuvo una correlación negativa entre el comportamiento reproductivo y el nivel de cortisol $(r=-0.693)$ (Tabla 2$)$ 
Tabla 2 Correlación entre la expresión de la conducta reproductiva de las hembras y la concentración de: estradiol, progesterona y cortisol. $\left({ }^{*}\right)$ Denota que la correlación es significativa $(P<0.05)$

\begin{tabular}{|l|l|l|l|l|}
\hline \multicolumn{5}{|c|}{ Correlación } \\
\hline & & E2 & P4 & CT \\
\hline Conducta. Control & Correlación de Pearson & $0.684^{*}$ & $0.743^{*}$ & -0.356 \\
\hline Conducta. Estrés & Correlación de Pearson & $0.829^{*}$ & 0.586 & $-0.693^{*}$ \\
\hline
\end{tabular}




\section{Machos}

\section{Cortisol}

Las diferencias en la concentración de cortisol entre los machos del grupo control y el grupo de estrés fueron significativas $(F=5.693 ; p<0.05)$. En el grupo control la concentración más alta de cortisol fue de $29.6 \mathrm{ng} / \mathrm{mL}$ y la más baja fue de $15 \mathrm{ng} / \mathrm{mL}$. En el grupo de estrés el valor promedio más alto fue de $56.01 \mathrm{ng} / \mathrm{mL}$ y el más bajo fue de $39.79 \mathrm{ng} / \mathrm{mL}$ (Figura 16).

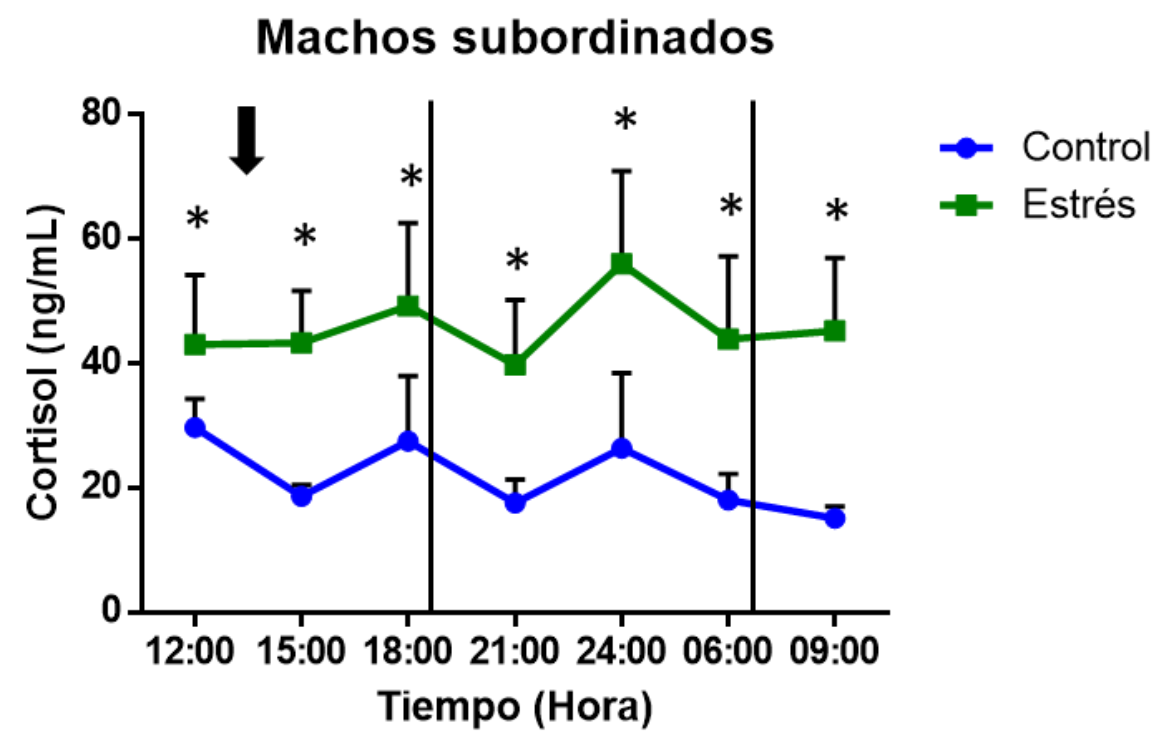

Figura 16. Concentración de cortisol en suero de machos subordinados durante un periodo de $24 \mathrm{~h}$ (media + EEM). La línea azul indica el grupo control y la línea verde el grupo de estrés. La flecha muestra el momento en el que los animales fueron alimentados y las líneas verticales delimitan los periodos del día y la noche. Diferencias significativas entre los grupos en cada hora se indican como ${ }^{*} p<0.05$. 
Con respecto a los sementales, la variación circadiana del cortisol fue similar en ambos, pero a diferentes niveles. Las fluctuaciones en esta hormona fueron similares a las obtenidas en los machos subordinados, siendo más altas las concentraciones en el semental sujeto a condiciones de estrés crónico que en el semental control. No se realizó análisis estadístico entre los sementales dado que solo se tenía un semental por grupo (Figura 17).

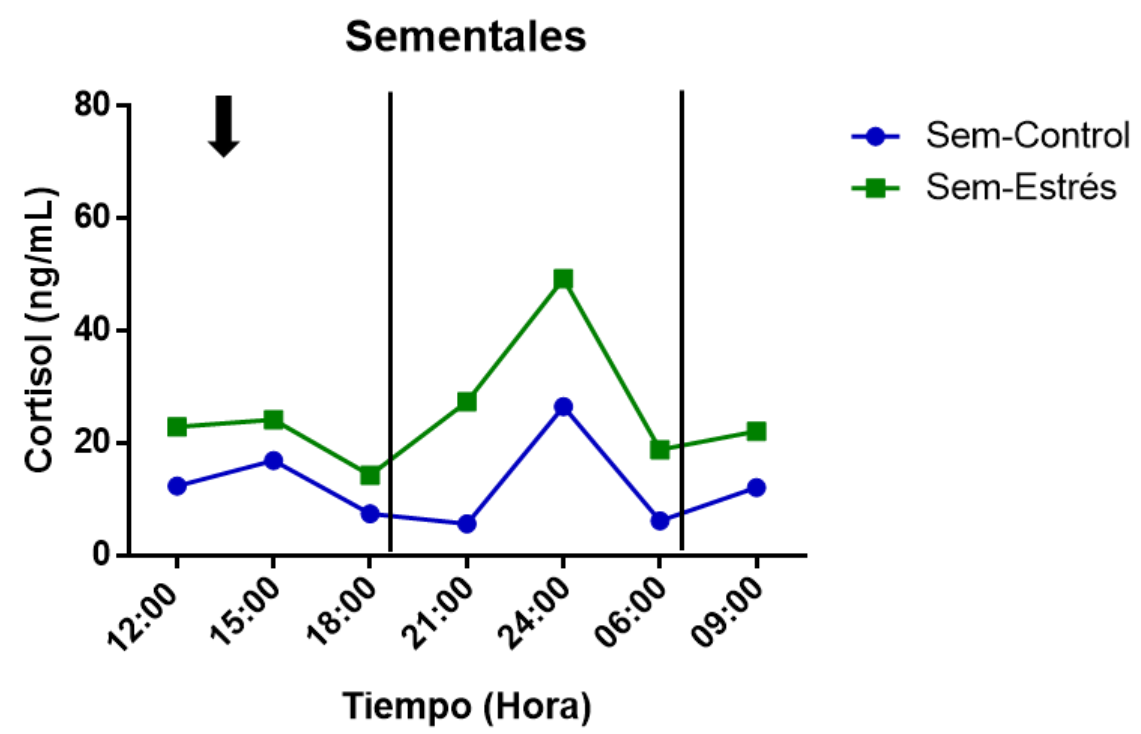

Figura 17. Se observa la concentración de cortisol en suero de sementales (Control $n=1$; Estrés $n=1)$ durante un periodo de $24 \mathrm{~h}$. La flecha muestra el momento en el que los animales fueron alimentados y las líneas verticales delimitan los periodos del día y la noche. 


\section{Parámetros reproductivos}

\section{Testosterona}

Antes de iniciar la reproducción (Diciembre), los niveles séricos de testosterona fueron significativamente mayores en los machos del grupo control $(2.08 \mathrm{ng} / \mathrm{mL})$ que en los machos del grupo de estrés crónico $(1.04 \mathrm{ng} / \mathrm{mL} ; \mathrm{t}=2.394 ; \mathrm{p}<0.05)$. Durante la reproducción (Enero) también se observaron diferencias significativas entre los grupos ( $\mathrm{t}=2.214 ; \mathrm{p}<0.05$ ), con un promedio de $3.63 \mathrm{ng} / \mathrm{mL}$ en los machos del grupo control y $1.37 \mathrm{ng} / \mathrm{mL}$ en los machos del grupo de estrés. En los machos de ambos grupos se

observó un aumento de la concentración sérica de testosterona cuando inicio la reproducción, en comparación con la concentración obtenida antes de la reproducción; sin embargo, sólo en el grupo control fue significativa la diferencia entre las concentraciones de testosterona antes y durante la actividad reproductiva $(t=-2.469$; $\mathrm{p}<0.05$, Figura 16).

Los sementales presentaron mayores niveles de testosterona que los machos subordinados. La concentración de testosterona en los sementales antes de la reproducción (diciembre) fue de $5.82 \mathrm{ng} / \mathrm{mL}$ en el semental control y $5.93 \mathrm{ng} / \mathrm{mL}$ en el semental de estrés. Durante la reproducción (enero) los niveles de testosterona incrementaron a $9.37 \mathrm{ng} / \mathrm{mL}$ en el control y $8 \mathrm{ng} / \mathrm{mL}$ en el estrés (Figura 18). 


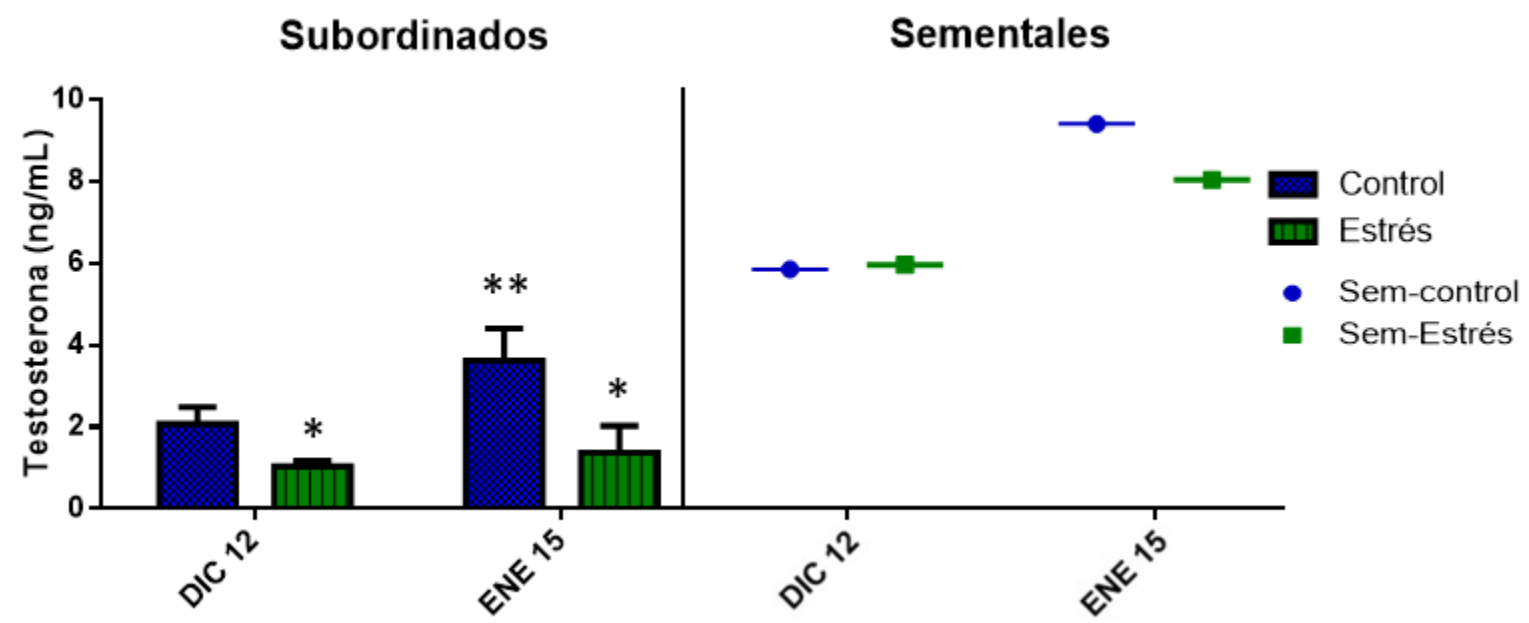

Figura 18. Concentración de testosterona (media $\pm E E$ ) antes y durante la reproducción. Las barras en color azul indican el grupo control y las barras en color verde representan al grupo de estrés. La concentración de testosterona en el semental de cada grupo está representada con una línea (azul: control; verde: estrés). $\left({ }^{*}\right)$ Indica diferencias significativas $(p<0.05)\left({ }^{* *}\right)$ indica diferencias significativas en el mismo grupo.

\section{Comportamiento reproductivo}

En la observación del comportamiento reproductivo en machos, se obtuvieron diferencias significativas para las conductas de: olfateo anogenital, lengüeteo e intentos de monta $(p<0.05)$. Para las conductas de: automarcaje, reflejo de Flehmen, pataleo, balido y monta no hubo diferencias significativas. Sólo los sementales de cada grupo, presentaron todas las conductas evaluadas. En la tabla 3 se muestra el porcentaje total de machos que presentaron cada una de las conductas de ambos grupos. 
Tabla 3. Etograma que muestra las conductas presentadas entre los grupos de machos. (*) Denota diferencia significativa $(P<0.05)$ entre los grupos cuando las conductas $S I$ fueron presentadas

\begin{tabular}{|c|c|c|c|c|c|c|}
\hline \multicolumn{7}{|c|}{ Etograma } \\
\hline & \multicolumn{3}{|c|}{ Control } & \multicolumn{3}{c|}{ Estrés } \\
\hline Conducta & $\mathbf{\% ~ S I ~}$ & $\%$ NO & Total & \% SI & $\%$ NO & Total \\
\hline Automarcaje & $\mathbf{2 0}$ & 80 & 100 & $\mathbf{1 0}$ & 90 & 100 \\
\hline Olfateo anogenital & $\mathbf{8 0}$ & 20 & 100 & $\mathbf{4 0}$ & 60 & 100 \\
\hline Legüeteo & $\mathbf{6 0}$ & 50 & 100 & $\mathbf{1 0}$ & 90 & 100 \\
\hline Flehmen & $\mathbf{1 0 0}$ & 0 & 100 & $\mathbf{7 0}$ & 0 & 100 \\
\hline Pataleo & $\mathbf{4 0}$ & 60 & 100 & $\mathbf{1 0}$ & 90 & 100 \\
\hline Balido & $\mathbf{6 0}$ & 40 & 100 & $\mathbf{3 0}$ & 70 & 100 \\
\hline Intentos de monta & $\mathbf{5 0}$ & 50 & 100 & $\mathbf{2 0}$ & 80 & 100 \\
\hline Monta & $\mathbf{3 0}$ & 70 & 100 & $\mathbf{1 0}$ & 90 & 100 \\
\hline
\end{tabular}

Se obtuvo una correlación entre el comportamiento reproductivo de los machos y sus niveles de testosterona tanto en el grupo control $(r=0.847)$ como en el de estrés $(r=$ 0.784). La correlación con el cortisol en el grupo control no fue significativa. En el grupo de estrés, se obtuvo una correlación negativa entre el comportamiento reproductivo y el nivel de cortisol $(r=-0.727)$ (Tabla 4).

Tabla 4. Correlación entre la expresión de la conducta reproductiva de los machos y la concentración de: testosterona y cortisol ( $\left.{ }^{*}\right)$ Denota que la correlación es significativa $(P<0.05)$

\begin{tabular}{|l|l|r|l|}
\hline \multicolumn{3}{|c|}{ Correlación } & \multicolumn{1}{|c|}{ CT } \\
\hline Conducta. Control & Correlación de Pearson & $0.847^{*}$ & -0.328 \\
\hline Conducta. Estrés & Correlación de Pearson & $0.784^{*}$ & $-0.727^{*}$ \\
\hline
\end{tabular}




\section{DISCUSIÓN}

\section{Respuesta de estrés}

Los resultados obtenidos en este trabajo muestran que las concentraciones de cortisol, tanto en las hembras como en los machos bajo condiciones estresantes en las que se encuentran naturalmente (de hacinamiento y bajo consumo de agua), son significativamente mayores al compararlas con el nivel de cortisol en los animales del grupo control. En cabras, se ha observado que los niveles séricos de cortisol aumentan durante la noche o por la mañana (Kokkonen et al., 2001), las fluctuaciones y picos observados durante el día se deben a factores externos, por lo tanto, no se observa una variación circadiana (Eriksson y Teräväinen, 1989), es decir, las cabras mantienen un ritmo intrínseco débil y de baja amplitud en la liberación de cortisol. En las hembras control los niveles de cortisol obtenidos se encuentran dentro de los rangos normales descritos en cabras, 1-20 ng/mL (Eriksson y Teräväinen, 1989, Shamay et al., 2000, Johansson et al., 2003). En las hembras estresadas en cambio, el rango obtenido fue mayor, 25-45 ng/mL. En los machos control, el rango obtenido fue de $15-30 \mathrm{ng} / \mathrm{mL}$ y en los estresados fue de 40-55 ng/mL. Esta modificación en los niveles de cortisol por efecto del estrés podría considerarse como un caso de reostasis reactiva, ya que ésta se refiere a una condición o estado en el que según las necesidades o cambios ambientales, al no poderse reestablecer la homeostasis, se genera un cambio en el punto de regulación del parámetro fisiológico (Mrosovsky, 1990). Lo que se observó entonces, es un ajuste en los niveles de cortisol para poder adaptarse a esas condiciones de estrés crónico. Algunos reportes sugieren que la retroalimentación negativa que ejercen los glucocorticoides sobre la síntesis y liberación de $\mathrm{CRH}$ en el hipotálamo, puede verse afectada cuando los animales se encuentran expuestos a estrés crónico (Greco, 2002).

Se sabe que las hembras responden al estrés de forma más pronunciada que los machos, produciendo mayores niveles de ACTH y cortisol (Handa et al., 1994; Kirschbaum et al., 1992). En este trabajo, en los machos de ambos grupos se 
presentaron niveles más altos de cortisol en los machos que en las hembras e incluso más altos que los normales. Esto podría deberse a que durante la reproducción se añade un estresor más a los ya presentados, que es la dominancia y la competencia por las hembras. Esto se confirma con las concentraciones de cortisol observadas en el semental control (macho dominante), cuyos niveles son normales (12 $\mathrm{ng} / \mathrm{mL}$ ), a diferencia de los subordinados control, con valores de cortisol alrededor de $20 \mathrm{ng} / \mathrm{mL}$ y de más de $40 \mathrm{ng} / \mathrm{mL}$ en los estresados. Otro aspecto a considerar respecto a los altos niveles de cortisol en los machos, es la variación estacional que se presenta en esta hormona, pues se sabe que en los machos cabríos los niveles de cortisol aumentan durante el invierno (Al-Busaidi et al., 2008) y la evaluación en este trabajo se realizó en Enero (parte del invierno). De acuerdo con Silanikove (2000), quien ha descrito diferentes mecanismos por los cuales la cabra se adapta a diferentes condiciones de estrés, el mecanismo reostático que se observó en este estudio muestra que el bienestar de las cabras es un factor importante para asegurar resultados satisfactorios dentro de su producción y reproducción (Kruger, 2015).

Efecto del estrés en parámetros reproductivos

\section{-Hembras}

Los resultados obtenidos en este trabajo muestran que el eje adrenal se mantiene hiperactivo y esto parece afectar al eje gonadal, tanto en las hembras como en los machos. Los niveles de estradiol en el grupo de estrés durante la fase folicular fueron significativamente menores que en las hembras del grupo control. . Se sabe que el cortisol puede inhibir la producción de estradiol durante la fase folicular, como se ha observado en ovejas (Macfarlane et al., 2000), e incluso causar que se prolongue la fase lútea mediante la supresión de la síntesis de la prostaglandina F2a que se encarga de inducir la luteólisis para que comience un nuevo ciclo estral (Alam et al., 1989, Emesih et al., 1995). Además, la liberación de CRH durante situaciones de estrés suprime la liberación de estrógenos en las células de la granulosa, probablemente por la inhibición de complejos enzimáticos que participan en la síntesis 
de estrógenos (Liang et al., 2013). Las altas concentraciones de cortisol durante el estrés suprimen la frecuencia de los pulsos de LH suprimiendo de la secreción pulsátil de $\mathrm{GnRH}$, lo que conduce a la disminución de la producción de estradiol de los folículos en crecimiento (Dobson y Smith, 2000). Por otra parte, en los ovarios de diferentes especies, como roedores y humanos, la activación del sistema Fas (FasL) en células de la granulosa y células del cumulus, causa la agrupación de dominios de muerte intracelulares, los cuales se unen a una proteína citosólica de muerte llamada FADD (dominio de muerte asociado a Fas). FADD activa caspasas y desencadena la apoptosis en las células foliculares (Ju et al., 1995, Zeuner et al., 2003, Yuan et al., 2016). Los glucocorticoides, específicamente el cortisol, puede activar este sistema Fas y disminuir los factores de crecimiento e inducir la apoptosis en células de la granulosa, células del cumulus y en los ovocitos (Yuan et al., 2016). Por lo tanto, la disminución del estradiol durante la fase folicular en el grupo de estrés podría explicarse por estos mecanismos. Poco se sabe sobre los efectos del estrés y los niveles de cortisol en las características específicas de la conducta sexual en la cabra hembra y que son esenciales para el apareamiento en condiciones naturales. En ovejas se ha observado que el aumento en los niveles de cortisol inhibe la receptividad y la proceptividad durante el estro, lo que causa que los machos pasen menos tiempo con las hembras estresadas (Pierce et al., 2008). En este estudio, las hembras del grupo de estrés, presentaron un menor comportamiento reproductivo y menores concentraciones plasmáticas de estradiol $(r=0.829)$. Esta alta correlación entre estos parámetros reproductivos se ha observado también en vacas bajo condiciones de estrés (Stoebel y Moberg, 1982). Probablemente la disminución en la expresión de la conducta sexual en las hembras se deba a sus bajos niveles de estradiol, ya que en cabras, se ha observado que el estradiol regula la expresión y duración de la conducta sexual, especialmente la receptividad (Okada et al., 1998). A pesar de que en este trabajo no se obtuvieron diferencias significativas en la duración del ciclo estral y no se logró evaluar la fertilidad de las hembras, sí se observó que las situaciones de estrés pueden bloquear la expresión de la receptividad sexual en las cabras (Dobson y Smith, 1995). 


\section{-Machos}

Las condiciones de hacinamiento y falta de agua en las que se encuentran las cabras son factores de estrés debido a que activan al eje HHA. Además de esos estresores existen otros factores que pueden influir en la respuesta de estrés y en la reproducción en los machos. Las cabras son animales gregarios, es decir, viven en grupos y establecen jerarquías sociales. Los individuos dominantes tienen acceso prioritario a los recursos limitados, como la pareja o el alimento; de este modo, el costo-beneficio de pertenecer a un estatus social es un factor de estrés para el individuo (Álvarez, 2008). Por lo tanto, los animales subordinados se encuentran más estresados dado su estatus social. A pesar de que en este trabajo no se realizó una evaluación del comportamiento agonístico, se pudo observar que en el grupo de estrés había una mayor presencia de comportamiento agonístico. Esto podría ser debido a que las interacciones entre los individuos funcionan como mediadores en la resolución de conflictos (Keil y Sambraus, 1998) generados por las condiciones en las que se encuentran. Los resultados obtenidos en este trabajo confirman lo anterior, pues los machos subordinados presentaron niveles de cortisol más altos que los sementales, así como menores niveles testosterona. Asimismo, los machos subordinados del grupo control, mostraron niveles plasmáticos de testosterona más altos que los machos subordinados del grupo de estrés, antes y durante la actividad reproductiva. Los niveles plasmáticos de testosterona en el grupo control aumentaron de manera significativa al inicio de la actividad reproductiva, lo que indica la activación del eje reproductivo. En cambio, en los machos estresados no se modificaron las concentraciones plasmáticas de testosterona al iniciar la reproducción, debido probablemente a los altos niveles de cortisol. Se sabe que los glucocorticoides pueden inhibir la señalización endocrina en el eje reproductivo del macho actuando directamente sobre el hipotálamo y la hipófisis, reduciendo la secreción de $\mathrm{GnRH}$ y LH, respectivamente (Breen y Karsh 2006, Dobson et al., 2012). A nivel testicular, las células de Leydig, productoras de testosterona, expresan receptores para glucocorticoides, los cuales inhiben directamente la transcripción de genes que 
codifican enzimas requeridas para la síntesis de testosterona (Orr et al., 1994) y por lo tanto, disminuye su liberación (Sapolsky et al., 2000, Hardy et al., 2005). También disminuyen el contenido de receptores testiculares a LH (Mann et al., 1987) y reducen el número de células de Leydig al promover en ellas la apoptosis (Gao et al., 2002, Juárez-Rojas et al., 2015, Kheirabad et al., 2016). La alta correlación negativa observada en este trabajo entre la expresión de la conducta sexual y el cortisol indica que efectivamente los altos niveles de cortisol tienen efectos negativos sobre la expresión del comportamiento reproductivo (control: $r=-0.328$; estrés: $r=-0.727$ ), así como en los niveles de testosterona (control: $r=-0.847$; estrés: $r=-0.784$ ). E comportamiento sexual en el macho puede ser el aspecto más vulnerable de la reproducción masculina, ya que es sensible a los factores de estrés (Retana-Márquez et al., 2003). Los efectos del estrés en el comportamiento reproductivo podrían implicar mecanismos inhibitorios centrales en el área preóptica medial (MPOA) por la liberación de $\mathrm{CRH}$. Este neuropéptido puede estimular la liberación de opioides endógenos como las beta-endorfinas, las cuales pueden inhibir la fase consumatoria de la conducta sexual, como se ha observado en ratas (Retana-Márquez et al., 2009). En especies como los roedores se ha descrito que la testosterona media la expresión del comportamiento sexual masculino mediante la unión del receptor de andrógenos y la aromatización de estos en el hipotálamo, la amígdala y el área preóptica (Alexander et al., 1993, Pak et al., 2002). La amígdala ha mostrado tener un papel importante en la expresión de la conducta de Flehmen en rumiantes (Hartz y Leedy, 1985). Se sabe poco sobre la regulación neuroendocrina de la conducta sexual en el macho cabrío. Sin embargo, recientemente se ha descrito que, al igual que en roedores, los machos cabríos también requieren de la presencia de estrógenos para alcanzar la madurez sexual y expresar su conducta reproductiva, ya que se ha encontrado que la enzima aromatasa está presente en células de los túbulos seminíferos y en células de Leydig antes de la pubertad y continua presente aun después de esta etapa (Ortiz et al., 2015). También han encontrado pequeñas cantidades circulantes de 17ß-Estradiol. Los efectos del estrés sobre el comportamiento sexual dependen de las características del factor de estrés (Retana-Márquez et al., 2003). Sin embargo, si los glucocorticoides 
son capaces de inhibir la síntesis y liberación de hormonas sexuales, probablemente desde etapas tempranas, donde se requiere la presencia de esteroides gonadales para alcanzar la madurez sexual, es probable que las alteraciones neuroendocrinas causadas por el estrés estén afectando el comportamiento reproductivo de los machos en este estudio.

A pesar del gran número de investigaciones sobre los efectos del estrés en la liberación de gonadotropinas y esteroides gonadales en una gran variedad de especies, poco se ha estudiado en los caprinos. Este trabajo aporta información importante en este sentido, ya que se demostró que existe una correlación negativa entre el aumento de cortisol y la supresión de esteroides gonadales, así como la expresión de la conducta reproductiva en cabras que se encuentran en condiciones de estrés ambiental por falta de agua y social por hacinamiento. 


\section{CONCLUSIONES}

El hacinamiento y el bajo consumo de agua son factores de estrés que afectan a las cabras, generando incremento en las concentraciones plasmáticas de cortisol.

Las cabras se adaptan a esas condiciones ambientales estresantes mediante un mecanismo de reostasis reactiva.

La activación del eje adrenal a causa de los factores estresantes repercute en bajos niveles plasmáticos de estradiol y progesterona en las hembras, lo cual altera su comportamiento reproductivo.

En los machos subordinados y en el semental, los niveles de testosterona también se ven afectados por la respuesta de estrés al hacinamiento y el acceso limitado al agua. 


\section{BIBLIOGRAFÍA}

Abdelatif A, M., \& Ahmed M, M. M. (1994). Water Restriction, Thermoregulation, Blood Constituents and Endocrine Responses in Sudanese Desert Sheep. Journal of Arid Environments, 26 (2) 171-180.

Abioja, M. O., Osinowo, O. A., Adebambo, O. A., Bello, N. J., \& Abiona, J. A. (2010). Water Restriction in Goats during Hot-Dry Season in the Humid Tropics: Feed Intake and Weight Gain. Archivos de Zootecnia, 59 (226) 195-203.

Adogla-Bessa, T., \& Aganga, A. A. (2000). Responses of Tswana goats to various lengths of water deprivation. South African Journal of Animal Science, 30 (1) 8791.

Aganga, A., Umunna, N., Oyedipe, E., \& Okoh, P. (1989). Breed differences in water metabolism and body composition of sheep and goats. The Journal of Agricultural Science, 113 255-258.

Alam M, G. S., Ahmed, J. U., \& Jahan, S. (1989). Effect of dexamethasone on the estrous cycle length in Black Bengal goats (Capra hircus). Theriogenology, 31 935-941.

Alamer, M. (2010). Effect of Water Restriction on Thermoregulation and Some Biochemical Constituents in Lactating Aardi Goats During Got Weather Conditions. Scientific Journal of King Faisal University (Basic and Applied Sciences), 11 (2) 189-205.

Al-Busaidi, R., Johnson, E. H., \& Mahgoub, O. (2008). Seasonal variations of phagocytic response, immunoglobulin $\mathrm{G}(\mathrm{IgG})$ and plasma cortisol levels in Dhofari goats. Small Ruminant Research, 79 (2) 118-123.

Alejandro , C. I., Villa M, A., Olivares P, J., \& Sánchez A, P. (2014). Environmental Stress Effect on Animal Reproduction. Journal of Animal Science, 4 (2) 79-84. 
Alexander B, M., Perkins, A., Vankirk E, A., Moss G, E., \& Fitzgerald J, A. (1993). Hypothalamic and Hypophyseal Receptors for Estradiol in High and Low Sexually Performing Rams. Hormones and Behavior, 27 (3) 296-307.

Altieri, M., Anta F, S., Caballero, J., Hernández, J., \& Noriega, M. (2006). Manejo de Agua y Restauración Porductiva en la Región Indígena Mixteca de Puebla y Oaxaca. En M. Altieri. México, D.F.: Banco Internacional de Reconstrucción y Fomento.

Álvarez, L. (2008). Efectos negativos del estrés sobre la reproducción en animales domésticos. Archivos de Zootecnia, 57 (R) 39-59.

Álvarez, L., \& Ducoing, A. (2009). Aspectos Reproductivos en el Ganado Caprino. Obtenido de http://amaltea.fmvz.unam.mx/

Andersen I, L., Roussel , S., Ropstad, E., Braastad B, O., Steinheim, G., Janczak, A. M., \& Boe K, E. (2008). Social instability increases aggression in groups of dairy goats, but with minor consequences for the goats' growth, kid production and development. Applied Animal Behavior Science, 114 (1) 132-148.

Aréchiga C, F., Aguilera j, I., Rincón R, M., Méndez de Lara , S., Bañuelos V, R., \& Meza-Herrera C, A. (2008). Situación actual y perspectivas de la producción caprina ante el reto de la globalización. Tropical and Subtropical Agroecosystems , 9: 1-14.

Arendt, J. (1998). Melatonin and the pineal gland: influence on mammalian seasonal and circadian physiology. Reviews of Reproduction, 3 13-22.

Arias M, L., Soriano R, R., Sánchez V, E., \& González E, C. (2012). Effect of the supplementation with multinutritional blocks of pitaya (Stenocereus griseus L.) on the live weight gain of goats in the low Mixteca of Oaxaca, México. . Effect of the supplementation with multinutritional blocks of pitaya (Stenocereus griseus L.)Livestock Research for Rural Development, 24: 119. 
Arroyo, J. (2011). Estacionalidad reproductiva de la oveja en México. Tropical and subtropical agroecosystems, 14 829-845.

Avalos C, R., Leyva C, J., Sánchez H, M., \& Osuna A, J. (2009). Guía para la alimentación de caprinos en Baja California Sur. INIFAP. Folleto para productores. La Paz, Baja California Sur, México.

Barrell, G., Thrun, L., Brown, M., Viguié, C., \& Karsch, F. (2000). Importance of photoperiodic signal quality to entrainment of the circannual reproductive rhythm of the ewe. Biology of Reproduction, 63 769-774.

Bauernfeind, M., \& Holtz, W. (1990). . Progesterone and estrogen levels in serum of cycling goats measured by enzyme immunoassay. Small ruminant research, 6 (1) 95-102.

Berumen B, M. E. (2004). Región Mixteca. Huajuapan de León, Oaxaca. México: Eumed. Net.

Breen K, M., Billings H, J., Wagenmaker E, R., Wessinger E, W., \& Karsch F, J. (2005). Endocrine Basis for Disruptive Effects of Cortisol on Preovulatory Events. Endocrinology , 146 (4) 2107-15.

Breen, K., \& Karsch, F. (2006). New Insights Regarding Glucocorticoids, Stress and Gonadotropin Suppression. Frontiers in Neuroendocrinology, 27(2) 233-45.

Bronson F, H., \& Heideman P, D. (1994). Seasonal regulation of reproduction in mammals. En K. E, \& D. Neil J, The Physiology of Reproduction (págs. 541584). New York: Raven Press.

Bustos O, E., \& Torres D, L. (2012). Reproducción Estacional En El Macho. International Journal of Morphology, 30 (4) 1266-79.

Chemineau, P., Malpaux, B., Delgadillo, J. A., Guerin, Y., Ravault, J. P., Thimonier, J., \& Pelletier, J. (1992). Control of sheep and goat reproduction: use of light and melatonin. Animal Reproduction Science, 30 (1) 157-184. 
Chrousos G, P., Torpy D, J., \& Gold P, W. (1998). Interactions between the Hypothalamic-Pituitary-Adrenal Axis and the Female Reproductive System: Clinical Implications. Annals of Internal Medicine, 129 (3) 229-40.

CNOG. (2012). Confederación Nacional de Organizaciones Ganaderas. "Cuenta México con el Ganado Caprino más importante de América". Obtenido de http://www.cnog.org.mx/

CNSP. (2012). Boletín. Comité Nacional Sistema Producto Caprinos. México.

CONAPO. (2010). Consejo Nacional de Población. Índice absoluto de marginación en México. Obtenido de http://www.conapo.gob.mx/

Coolen L, M., J, A., Truitt W, A., \& McKenna K, E. (2004). Central regulation of ejaculation. Physiology y Behavior, 83 (2) 203-215.

Dantzer, R., \& Mormède, P. (1983). Stress in farm animals: a need for reevaluation. Journal of Animal Science, 57 (1) 6-18.

Delgadillo, J. A., Canedo, G., Chemineau, P., Gullaume, D., \& Malpaux, B. (1999). Evidence for an annual reproductive rhythm independent of food availability in male Creole goats in subtropical Northern Mexico. Theriogenology, 52 727-737.

Dobson, H., \& Smith R, F. (1995). Stress and Reproduction in Farm Animals. Journal of Reproduction and Fertility, 49: 451-61.

Dobson, H., \& Smith R, F. (2000). What Is Stress, and How Does It Affect Reproduction? Animal Reproduction Science, 60-61: 743-52.

Dobson, H., Fergani, C., Routly J, E., \& Smith R, F. (2012). Effects of Stress on Reproduction in Ewes. Animal Reproduction Science, 130 (3-4) 135-40.

Dobson, H., Tebble J, E., Smith R, F., \& Ward W, R. (2001). Is Stress Really All That Important? Theriogenology, 55 (1) 65-73. 
Dominguez, J., Riolo J, V., Xu, Z., \& Hull E, M. (2001). Regulation by the medial amygdala of copulation and medial preoptic dopamine release. Journal of Neuroscience, 21 (1) 349-355.

Duarte, J., Flores, J., Malpaux, B., \& Delgadillo, J. (2008). Reproductive seasonality in female goats adapted to a subtropical. Domestic Animal Endocrinology, $35362-$ 370.

Dukes, \& Reece O, W. (2004). Fisiología de los Animales Domésticos. México, D.F: Acribia.

Emesih G, C., Newton G, R., \& Weise D, W. (1995). Effects of heat stress and oxytocin on plasma concentrations of progesterone and 13,14-dihydro-15ketoprostaglandin F2a in goats. Small Ruminant Research, 16 (2) 133-139.

Eriksson, L., \& Teravainen T, L. (1989). Circadian Rhythm of Plasma Cortisol and Blood Glucose in Goats. Asian-Australasian Journal of Animal Sciences, 2 (3) 202-3.

Escobar M, F. J. (2000). Estacionalidad Reproductiva de la Cabra. Unidad Académica de Medicina Veterinaria y Zootecnia de la Universidad Autónoma de Zacatecas. Obtenido de http://www.uaz.edu.mx/

Fabre-Nys, C. (2000). Le Comportement Sexuel Des Caprins: Contrôle Hormonal et Facteurs Sociaux. INRA Prod. Anim, 13 (1) 11-23.

Fabre-Nys, C., \& Gelez, H. (2007). Sexual Behavior in Ewes and Other Domestic Ruminants. Hormones and Behavior, 52 (1) 18-25.

Fatet, A., Maria-Teresa P, R., \& Bernard, L. (2011). Reproductive Cycle of Goats. Animal Reproduction Science, 124 (3) 211-19.

Ferraro, S., Bravo, M., Pérez, G., \& Ballarales, P. (2009). Efecto de Miniimplantes de Melatonina Sobre Algunas Variables Reproductivas en Cabras Canarias de Alto Mestizaje en Condiciones de Trópico. Gaceta de Ciencias Veterinarias , 14 (1) 20-24. 
Finch V, A. (1986). Body Temperature in Beef Cattle: Its Control and Relevance to Production in the Tropics. Journal of Animal Science, 62 (2) 531.

Fuente H, J., Garmendia, G., González, H., Jiménez, E., \& Mascorro, V. (1989). Bonanza y crisis de la ganadería nacional: una visión integral de la actividad agropecuaria en México. Subdirección de Investigación. Departamento de Diagnóstico Externo. Universidad Autónoma de Chapingo, México.

Gaafar K, M., Mohamed K, G., \& Doaa F, T. (2005). The Hormonal Profile during the Estrous Cycle and Gestation in Damascus Goats. Small Ruminant Research, 57 (1) 85-93.

Gao H, B., Tong M, H., Hu Y, Q., You H, Y., Guo Q, S., Ge R, S., \& Hardy M, P. (2002). Mechanisms of glucocorticoid-induced Leydig cell apoptosis. Molecular and Cellular Endocrinology, 199 (1-2) 153-163.

García, E. (2004). Modificaciones al sistema de Clasificación Climática de Köppen. México: Instituto de Geografía, ISBN-UNAM.

González S, C. (1993). Comportamiento Reproductivo de la Cabra Criolla en los Trópicos. Revista Cientifica FCV-LUZ, II (2) 143-151.

Graham M, D., \& Pfaus J, G. (2010). Differential regulation of female sexual behaviour by dopamine agonists in the medial preoptic area. Pharmacology Biochemistry and Behavior, 97 (2) 284-292.

Grandin, T. (1997). Assessment of stress during handling and transport. Journal of animal science, 75 (1) 249-257.

Greco, D. (2002). Endocrine glands and their function. En Veterinary Physiology (págs. 341-372). W. B. Saunders Company.

Guerrero A, R., Jiménez H, E., \& Santiago R, H. (2010). La transformación de los ecosistemas de la Mixteca Alta Oaxaqueña desde el Pleistoceno Tardío hasta el Holoceno. Ciencia y Mar, XIV (40) 61-68. 
Gupta, S., Earley, B., Ting S, T. L., \& Crowe M, A. (2005). Effect of repeated regrouping and relocation on the physiological, immunological, and hematological variables and performance of steers. Journal of Animal Science, 83 (8) 1948-1958.

Guyton A, C., \& Hall, J. (2006). Tratado de Fisiología Médica. Elsevier Health Sciences.

Hamzaoui, S., Salama, A. A., Albanell, E., Such, X., \& Caja, G. (2013). Physiological Responses and Lactational Performances of Late-Lactation Dairy Goats under Heat Stress Conditions. Journal of Dairy Science, 96 (10) 6355-65.

Handa, R. J., \& Weiser, M. J. (2014). Gonadal steroid hormones and the hypothalamopituitary-adrenal axis. Frontiers in Neuroendocrinology, 35 (2) 197-220.

Handa, R. J., Nunley, K. M., Lorens, S. A., Louie, J. P., McGivern, R. F., \& Bollnow, M. R. (1994). Androgen regulation of adrenocorticotropin and corticosterone secretion in the male rat following novelty and foot shock stressors. Physiology and Behavior, 55: 117-124.

Hardy M, P., Gao H, B., Dong, Q., Ge, R., Wang, Q., Chai W, R., .. Sottas, C. (2005). Stress hormone and male reproductive function. Cell and Tissue Research, 322 (1) 147-153.

Hartz B, L., \& Leedy M, G. (1985). Neurological Bases of Male Sexual Behavior. In Reproduction, edited by Norman Adler, Donald Pfaff, and Robert W. Goy. Handbook of Behavioral Neurobiology 7. Springer US, 373-422.

Herbison A, E. (2006). Physiology of the gonadotropin-releasing hormone neuronal network. En D. Neill J, The Physiology of Reproduction (págs. 1415-1482). New York: Elsevier.

Hernandez C, J. L., \& Zarco Q, A. (1998). Función del cuerpo Lúteo y Muerte Embrionaria en Rumiantes. Ciencia Veterinaria, 1-28. 
Hernández Z, J. (2000). La caprinocultura en el marco de la ganadería poblana (México): contribución de la especie caprina y sistemas de producción. Archivos de Zootecnia, 49 341-352.

Hernández, J., Pedraza, R., Franco, F., Villarreal, O., \& Camacho, J. (2011). Caracterización socioeconómica y productiva de unidades caprinas familiares en la Mixteca Poblana. Archivos de Zootecnia, 60 (230) 175-182.

Hernández, Z., Rodero, E., Herrera, M., Delgado, J., Barba, C., \& Sierra, A. (2001). La Caprinocultura en la Mixteca Poblana (México). Descripción e Identificación de Factores Limitantes. Archivos de Zootecnia, 50 231-239.

Hull, E. M., \& Dominguez, J. M. (2006). Getting his act together: Roles of glutamate, nitric oxide, and dopamine in the medial preoptic area. Brain Research, 1126 (1) $66-75$.

INAFED. (2010). Insituto Nacional para el Federalismo y el Desarrollo Municipal. Secretaría de Gobernación, Centro Nacional de Estudios Municipales, Gobierno del Estado de Oaxaca. Obtenido de Los Municipios de Oaxaca, Enciclopedia de los Municipios de México. Talleres Gráficos de la Nación: http://www.inafed.gob.mx/

Johansson, A., Eriksson, A. L., Soveri, T., \& Laakso, M. L. (2003). Serum Cortisol Levels in Goats Exhibit Seasonal But Not Daily Rhythmicity. Chronobiology International, 20 (1) 65-79.

Ju S, T., Panka D, J., Cui, H., Ettinger, R., el-Khatib, M., Sherr D, H., . . MarshakRothstein, A. (1995). Fas(CD95)/FasL Interactions Required for Programmed Cell Death after T-Cell Activation. Nature, 373 (6513) 444-48.

Juárez R, A. L., García L, M., Aragón M, A., Gómez Q, L. E., \& Retana M, M. d. (2015). Intrinsic and Extrinsic Apoptotic Pathways Are Involved in Rat Testis by Cold Water Immersion-Induced Acute and Chronic Stress. Systems Biology in Reproductive Medicine, 61 (4) 211-21. 
Kadzere C, T., Murphy M, R., Silanikove, N., \& Maltz, E. (2002). Heat Stress in Lactating Dairy Cows: A Review. Livestock Production Science , 77 (1) 59-91.

Kannan, G., Kouakou, B., Terrill T, H., \& Gelaye, S. (2003). Endocrine, blood metabolite, and meat quality changes in goats as influenced by short-term, preslaughter stress. Journal of Animal Science, 81 (6) 1499-1507.

Kannan, G., Terrill T, H., Kouakou, B., Gazal O, S., Gelaye, S., Amoah E, A., \& Samaké, S. (2000). Transportation of Goats: Effects on Physiological Stress Responses and Live Weight Loss. Journal of Animal Science, 78 (6) 1450-57.

Katz L, S., Price E, O., Wallach S, J. R., \& Zenchak J, J. (1988). Sexual performance of rams reared with or without females after weaning. Journal Animal Science, 66 (5) 1166-1173.

Keil N, M., \& Sambraus H, H. (1998). Interveners in agonistic interactions amongst domesticated goats. Z Sâgetierkunde, 63: 266-272.

Kheirabad M, K., Khodabandeh, Z., Rahmanifar, F., Tamadon, A., Jahromi B, N., Owjfard, M., \& Koohi-Hosseinabadi, O. (2016). Testicular Germ Cells Apoptosis Following Exposure to Chronic Stress in Rats. Asian Pacific Journal of Reproduction, 5 (5) 371-75.

Kirschbaum, C., Wüst, S., \& Hellhammer, D. (1992). Consistent sex differences in cortisol responses to psychological stress. Psychosomatic Medicine, 54 (6) 648657.

Kokkonen, U., Riskilä, P., Roihankorpi, M., \& Soveri, T. (2001). Circadian variation of plasma atrial natriuretic peptide, cortisol and fluid balance in the goat. Acta Physiologica Scandinavica, 171: 1-8.

Koolhaas J, M., Bartolomucci, A., Buwalda, B., de Boer S, F., Flügge, G., Korte S, M., ... E, F. (2011). Stress Revisited: A Critical Evaluation of the Stress Concept. Neuroscience and Biobehavioral Reviews, 35 (5) 1291-1301. 
Kruger L, P. (2015). The Effect of Environmental Factors and Husbandry Practices on Stress in Goats. small Ruminant Research, 141: 1-4.

Landaeta H, A. J., Giangreco, M., Meléndez, P., Bartolomé, J., Bennet, F., Rae D, O., ... Archbald, L. F. (2004). Effect of Biostimulation on Uterine Involution, Early Ovarian Activity and First Postpartum Estrous Cycle in Beef Cows. Theriogenology , 61 (7-8) 1521-32.

Lehman M, N., Coolen L, M., \& Goodman R, L. (2010). Minireview: kisspeptin/neurokinin B/dynorphin (KNDy) cells of the arcuate nucleus: a central node in the control of gonadotropin-releasing hormone secretion. Endocrinology, 151: 3479-3489.

Liang, B., Wei D, L., Cheng Y, N., Yuan H, J., Lin, J., Cui X, Z., . . Tan J, H. (2013). Restraint Stress Impairs Oocyte Developmental Potential in Mice: Role of $\mathrm{CRH}$ Induced Apoptosis of Ovarian Cells. Biology of Reproduction, 89 (3) 64.

Llewelyn C, A., Perrie, J., Luckins A, G., \& Munro C, D. (1993). estrus in the British White Goat: Timing of Plasma Luteinizing Hormone Surge and Changes in Behavioural and Vaginal Traits in Relationship to Onset of Oestrus. The British Veterinary Journal, 149 (2) 171-82.

Macfarlane M, S., Breen K, M., Sakurai, H., Adams B, M., \& Adams T, E. (2000). Effect of duration of infusion of stress-like concentrations of cortisol on follicular development and the preovulatory surge of LH in sheep. Animal Reproduction Science, 63 (3-4) 167-175.

Malena, M., Voslářová, E., Kozák, A., Bělobrádek, P., Bedáňová, I., Steinhauser, L., \& Večerek, V. (2007). Comparison of Mortality Rates in Different Categories of Pigs and Cattle during Transport for Slaughter. Acta Veterinaria Brno, 76 (8) S109-S116.

Malpaux, B., Thiéry, J., \& Chemineau, P. (1999). Melatonin and the seasonal control of reproduction. Reproduction Nutrition Development, 39 355-366. 
Mani, A. U., Watson, E. D., \& Mckelvey, W. A. (1994). The effects of subnutrition before and embryo transfer on pregnancy rate and embryo survival in does. Theriogenology, 41: 1673-1678.

Mann D, R., Free, C., Nelson, C., Scott, C., \& Collins D, C. (1987). Mutually independent effects of adrenocorticotropin on luteinizing hormone and testosterone secretion. Endocrinology, 120: 1542-1550.

Manuales del ganado caprino, 4. (s.f.). Obtenido de Sistema Nacional de Información para el Desarrollo rural Sustentable. Noviembre 2016: http://www.camponl.gob.mx/

Mastorakos, G., Pavlatou M, G., \& Mizamtsidi, M. (2006). The hypothalamic-pituitaryadrenal and the hypothalamic- pituitary-gonadal axes interplay. Pediatric Endocrinology Reviews, 3 (1) 172-181.

Mrosovsky, N. (1990). Rheostasis: the physiology of change. New York: Oxford University Press.

Okada, M., Hamada, T., Takeuchi, Y., \& Mori, Y. (1996). Timing of Proceptive and Receptive Behavior of Female Goats in Relation to the Preovulatory LH Surge. The Journal of Veterinary Medical Science / the Japanese Society of Veterinary Science, 58 (11) 1085-89.

Okada, M., Takeuchi, Y., \& Mori, Y. (1998). Estradiol-Dependency of Sexual Behavior Manifestation at the Post-LH Surge Period in Ovarectomized Goat. Journal of Reproduction and Development, 44 53-58.

Orihuela T, A. (2014). Ram's sexual behavior. Review. Rev Mex Cienc Pecu, 5 (1) 4989.

Orr T, E., Taylor M, F., Bhattacharyya A, K., Collins D, C., \& Mann D, R. (1994). Acute immobilization stress disrupts testicular steroidogenesis in adult male rats by inhibiting the activities of 17a-hydroxylase and 17,20-lyase without affecting the binding of LH/hCG receptors. Journal of Andrology, 15: 302-308. 
Ortiz C, L., Valdez R, A., Mondragón J, A., Gariglio, P., Zarco, L., Valencia, J., \& Romano M, C. (2015). Estrogen Synthesis and Secretion during Postnatal Testicular Development in Male Goats: In Situ Aromatase mRNA Expression. Small Ruminant Research, 130: 146-52.

Pak T, R., Lynch G, R., \& Tsai P, S. (2002). Estrogen Accelerates Gonadal Recrudescence in Photo-Regressed Male Siberian Hamsters. Endocrinology, 143 (10) 4131-4134.

Pierce B, N., Hemsworth P, H., Rivalland E, T. A., Wagenmaker E, R., Morrissey A, D., Papargiris M, M., . . Tilbrook A, J. (2008). Psychosocial Stress Suppresses Attractivity, Proceptivity and Pulsatile LH Secretion in the Ewe. Hormones and Behavior , 54 (3) 424-34.

Pinilla, L., Aguilar, E., Dieguez, C., Millar R, P., \& Tena S, M. (2012). Kisspeptins and Reproduction: Physiological Roles and Regulatory Mechanisms. Physiological Reviews, 92 (3) 1235-1316.

Retana M, S., Bonilla J, H., Vázquez P, G., \& Martínez G, R. (2009). Naltrexone effects on male sexual behavior, corticosterone, and testosterone in stressed male rats. Physiology and Behavior, 96 (2) 333-342.

Retana M, S., Bonilla J, H., Vázquez P, G., Martínez G, R., \& Velázquez M, J. (2003). Changes in Masculine Sexual Behavior, Corticosterone and Testosterone in Response to Acute and Chronic Stress in Male Rats. Hormones and Behavior, 44 (4) 327-37.

Rostgno, M. (2010). Stress in Farm Animals and Food Safety: Is there a Connection? Livestock Behavior Research Unit, 1-3.

Sakamoto, H. (2012). Brain-spinal cord neural circuits controlling male sexual function and behavior. Neuroscience Research, 72 (2) 103-116.

Sakatani, M., Alvarez N, V., Takahashi, M., \& Hansen P, J. (2012). Consequences of Physiological Heat Shock Beginning at the Zygote Stage on Embryonic 
Development and Expression of Stress Response Genes in Cattle. Journal of Dairy Science, 95 (6) 3080-91.

Salama, A. A., Caja, G., Hamzaoui, S., Badaoui, B., Castro C, A., Facanha D, A. E., \& Bozzi, R. (2014). Different Levels of Response to Heat Stress in Dairy Goats. Small Ruminant Research, 121 (1) 73-79.

Sapolsky R, M., Romero L, M., \& Munck A, U. (2000). How do glucocorticoids influence stress responses? Integrating permissive, suppressive, stimulatory, and preparative actions. Endocrinology, 2: 55-89.

Shamay, A., Mabjeesh S, J., Shapiro, F., \& Silanikove, N. (2000). Adrenocorticotrophic hormone and dexamethasone failed to affect milk yield in dairy goats: comparative aspects. Small Ruminant Research, 38 (3) 255-259.

Shelley, D. N., Choleris, E., Kavaliers, M., \& Pfaff, D. W. (2007). Mechanisms underlying sexual and affiliative behaviors of mice: Relation to generalized CNS arousal. ResearchGate , 1 (3) 260-70.

SIAP. (2014). Sistema de Información Agroalimentaria y Pesquera. Secretaria de Gobernación. Obtenido de http://www.gob.mx/siap/

Silanikove, N. (2000). Effects of Heat Stress on the Welfare of Extensively Managed Domestic Ruminants. Livestock Production Science, 67 (1-2) 1-18.

Smith J, T., \& Clarke I, J. (2010). Gonadotropin inhibitory hormone function in mammals. Trends in Endocrinology and Metabolism, 21: 255-60.

Smith M, J., \& Jennes, L. (2001). Neural Signal That Regulate GnRH Neurones Directly during the Oestrous Cycle. Reproduction, 122 (1) 1-10.

Soriano, R., Arias, L., Bonilla, O., \& Haro, J. (2011). Programa de desarrollo comunitario agropecuario y ambiental participativo en una comunidad Mixteca: Cosolotepec, Oaxaca. Desarrollo, Ambiente y Cultura, 1: 4-12. 
Steiger B, M., Senn, M., Sutter, F., Kreuzer, M., \& Langhans, W. (2001). Effect of Water Restriction on Feeding and Metabolism in Dairy Cows. merican Journal of Physiology. Regulatory, Integrative and Comparative Physiology, 280 (2) R41827.

Stoebel D, P., \& Moberg G, P. (1982). Effect of Adrenocorticotropin and Cortisol on Luteinizing Hormone Surge and Estrous Behavior of Cows. Journal of Dairy Science, 65 (6) 1016-24.

Tanriverdi, F., Silveira L, F., MacColl G, S., \& Bouloux P, M. (2003). The HypothalamicPituitary-Gonadal Axis: Immune Function and Autoimmunity. Journal of Endocrinology, 176 (3) 293-304.

Tilbrook A, J., Turner A, I., \& Clarke I, J. (2002). Stress and reproduction: central mechanisms and sex differences in non-rodent species. Stress (Amsterdam, Netherlands), 5 (2) 83-100.

Valencia, J., González, L., \& Díaz, J. (1996). . Actividad reproductiva de la cabra criolla en México en el examen postmortem del aparato genital. Veterinaria México, 17: $177-180$.

Vas, J., Chojnacki, R., Kjøren M, F., Lyngwa, C., \& Andersen I, L. (2013). Social interactions, cortisol and reproductive success of domestic goats (Capra hircus) subjected to different animal densities during pregnancy. Applied Animal Behaviour Science, 147 (1-2) 117-126.

Waas J, R., Ingram J, R., \& Matthews L, R. (1997). Physiological Responses of Red Deer (Cervus Elaphus) to Conditions Experienced during Road Transport. Physiology and Behavior, 61 (6) 931-938.

Waas J, R., Ingram J, R., \& Matthews L, R. (1999). Real-Time Physiological Responses of Red Deer to Translocations. The Journal of Wildlife Management, 63 (4) 1152-1162. 
Wolfenson, D., Thatcher W, W., Badinga, L., Savio J, D., Meidan, R., Lew B, J., . . Berman, A. (1995). Effect of Heat Stress on Follicular Development during the Estrous Cycle in Lactating Dairy Cattle. Biology of Reproduction, 52 (5) 110613.

Yuan H, J., Han, X., He, N., Wang G, L., Gong, S., Lin, J., . . Tan J, H. (2016). Glucocorticoids Impair Oocyte Developmental Potential by Triggering Apoptosis of Ovarian Cells via Activating the Fas System. Scientific Reports, 6: 24036.

Zeuner, A., Muller, K., Reguszynski, K., \& Jewgenow, K. (2003). Apoptosis within bovine follicular cells and its effect on oocyte development during in vitro maturation. Theriogenology, 59: 1421-1433.

Zhong R, Z., Liu H, W., Zhou D, W., Sun H, X., \& Zhao C, S. (2011). The Effects of Road Transportation on Physiological Responses and Meat Quality in Sheep Differing in Age. Journal of Animal Science, 89 (11) 3742-51. 